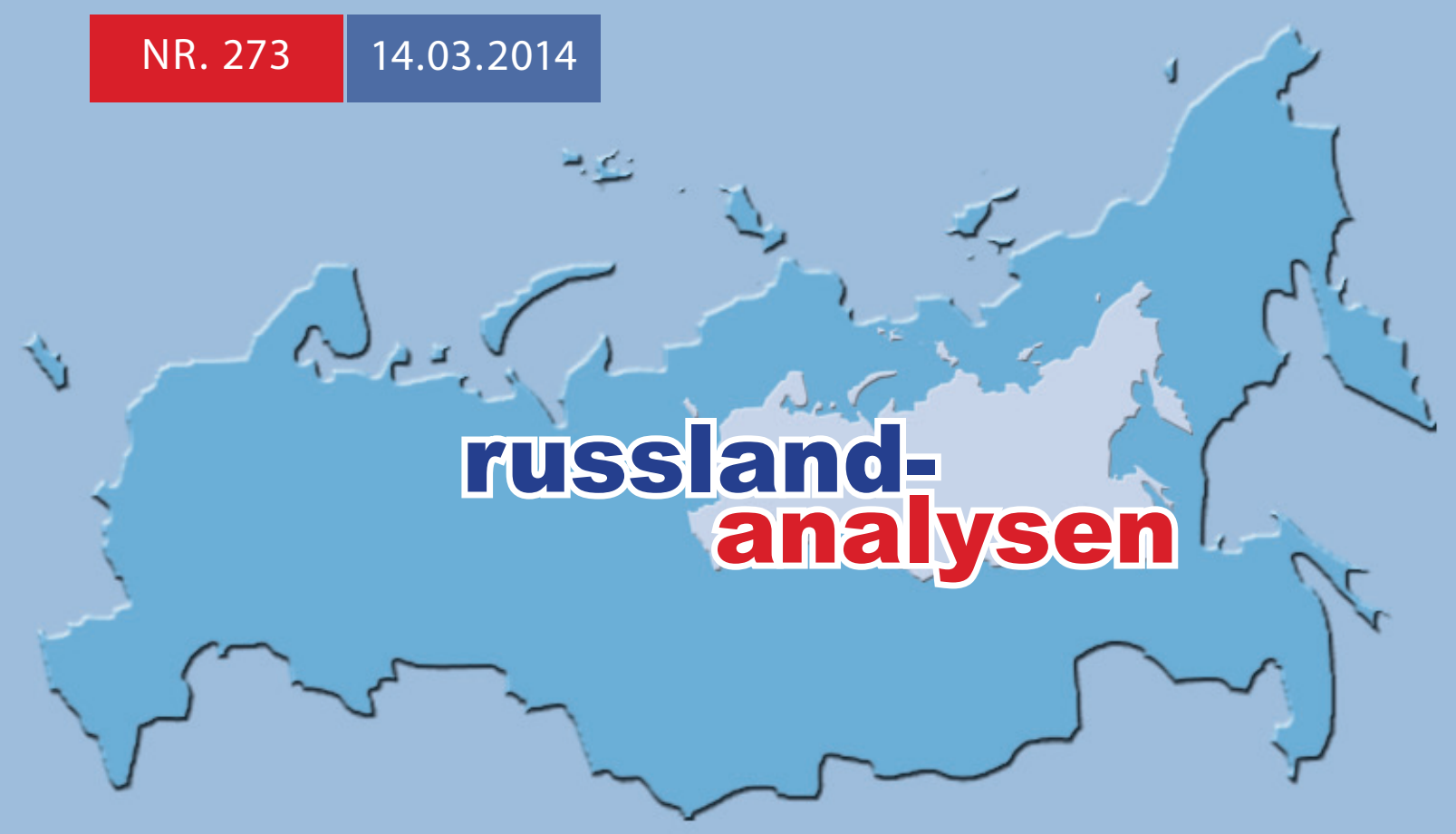

\title{
http://www.laender-analysen.de/russland/
}

\section{DIE RUSSLAND-KRISE}

\section{ANALYSE}

Die Hilfe des großen Bruders

Wie Russland die Krise in der Ukraine sieht

Susanne Spahn, Berlin

aNALYSE

Militärische Implikationen der Krim-Krise

Margarete Klein/ Kristian Pester, Berlin

- UMFRAGE

Die russischen Streitkräfte in Umfragen

- KOMMENTAR

Der Krim-Krieg findet nicht statt

Strategie und Taktik einer zielgerichteten Eskalation und eine mögliche Konfliktlösung

Benno Ennker, Konstanz

STATISTIK

Russland und die Ukraine: Wirtschaftsbeziehungen

- UMFRAGE

Russland und die Ukraine in aktuellen Meinungsumfragen

- PRESSESTIMMEN

Aus der russischen Presse

AUS RUSSISCHEN BLOGS

Krim: Kriegsszenarien und Sanktionen gegen Russland 24

NOTIZEN AUS MOSKAU

Andere Realitäten

Jens Siegert, Moskau

CHRONIK

28. Februar - 13. März 2014

- Deutsche Gesellschaft für Osteuropakunde e.V.
Forschungsstelle Osteuropa an der Universität Bremen
Alfried Krupp von Bohlen und Halbach Stiftung

\section{MANGOLD}




\section{Die Hilfe des großen Bruders \\ Wie Russland die Krise in der Ukraine sieht}

Susanne Spahn, Berlin

\section{Zusammenfassung}

Russland will seine Nachbarstaaten in der geplanten Eurasischen Wirtschaftsunion wirtschaftlich und politisch dominieren. Moskau hat Belarus und andere Staaten bislang mit wirtschaftlichen Druckmitteln vom Beitritt zum Einheitlichen Wirtschaftsraum »überzeugt«. In der Ukraine greift Moskau jetzt mit der Entsendung von Truppen auf die Krim direkt ein und verletzt die territoriale Integrität des Nachbarlandes. Das ist ein Beleg für die besondere Bedeutung, die die Ukraine wie auch Belarus als Teile einer angenommenen ostslawischen Gemeinschaft für Russland haben.

\section{Ein Teil der großen russischen Welt ...}

Warum beansprucht die russische Führung ein VetoRecht bei der Frage, welche außenpolitische Orientierung Kiew wählt? Mit welchem Recht mischt sich Russland in die inneren Angelegenheiten der Ukraine ein - ein Vorwurf, der bislang immer dem Westen gemacht wurde, bis Moskau Ende Februar, Anfang März Truppen auf die Krim entsandte und sich selbst die Maske der Neutralität in dem Konflikt herunterriss? Putin begründete dies beim EU-Russland-Gipfel in Brüssel Ende Januar mit der "gewissen Spezifik der Beziehungen zwischen Russland und der Ukraine«.

Was unter diesen spezifischen Beziehungen zu verstehen ist, führte Putin vor dem internationalen Diskussionsclub Waldaj im September 2013 aus: „Wir werden nicht vergessen, dass die heutige Staatlichkeit Russlands ihre Wurzeln am Dnepr hat. Die Kiewer Rus begann als Grundlage des zukünftigen riesigen russischen Staats. Wie haben eine gemeinsame Tradition, eine gemeinsame Mentalität, eine gemeinsame Geschichte, eine gemeinsame Kultur. Unsere Sprachen sind sehr ähnlich. In diesem Sinne, das will ich noch einmal wiederholen, sind wir ein Volk. « Das ukrainische Volk sei Teil »unserer großen russischen Welt, der russisch-ukrainischen«. Natürlich respektiere Russland die ukrainische Unabhängigkeit, auch die Wahl der Prioritäten und Bündnispartner sei das souveräne Recht des ukrainischen Volkes, versicherte der russische Präsident.

Dies ist jedoch Theorie, de facto gesteht die russische Führung der Ukraine nur eine eingeschränkte Souveränität zu. Das erwähnte Veto-Recht leitet Russland aus der gemeinsamen Zugehörigkeit zu einer ostslawischen Gemeinschaft von Russen, Ukrainern und Belarussen ab. In der Vergangenheit ist die ostslawische Gemeinschaft im Russischen Reich und in der Sowjetunion immer russisch dominiert gewesen, die Russen betrachteten die Ukrainer (oder einst: die "Kleinrussen«) und die Belarussen als Teil ihrer Nation oder allenfalls als jüngere Brüder.

\section{Eingeschränkte Souveränität}

Dass die Ukraine de facto nur über eingeschränkte Souveränität verfügt, demonstrierte Russland bereits im Herbst 2013, als es im Vorfeld des geplanten Assoziierungsabkommens der Ukraine mit der EU zeitweilig seine Grenzen für ukrainische Waren schloss. Die ukrainische Führung um Viktor Janukowytsch beugte sich dem russischen Druck. Moskau begründete dies mit wirtschaftlichen Schutzmaßnahmen. Da die Grenzen zwischen Russland und der Ukraine offen sind, könnten Billigwaren aus Europa über die Ukraine auch den russischen Markt überfluten, so die Argumentation. Die Ukraine solle den Weg nach Europa unter russischer Ägide beschreiten, so die Vorstellung Putins: Erst wenn Kiew der Zollunion von Russland, Belarus und Kasachstan beigetreten sei, könnten Verhandlungen über ein Freihandelsabkommen mit der EU geführt werden, erläuterte das Staatsoberhaupt vor dem Waldaj-Club. Moskau sei bereit, die krisengeschüttelte ukrainische Wirtschaft großzügig zu subventionieren: mit günstigen Energieträgern und dem freien Zugang zum russischen Markt. Neun Milliarden US-Dollar könnte die Ukraine damit jährlich einsparen, stellte Putin in Aussicht.

Damit schlägt Russland der Ukraine vor, dem Beispiel Belarus zu folgen. Als das Lukaschenka-Regime für russische Energie Marktpreise zahlen sollte und ständige Handelskriege und Importverbote für belarussische Waren die Wirtschaft des Landes erschütterten, befand sich Belarus 2010/2011 in einer Situation wie die Ukraine heute, nämlich kurz vor der Zahlungsunfähigkeit. Als die belarussische Führung unter Lukaschenka einlenkte, der Zollunion mit Russland beitrat und die Gaspipelines vollständig an "Gazprom« verkaufte, flossen die Subventionen wieder, der russische Markt war wieder offen. Lukaschenka kann seitdem die unreformierte belarussische Wirtschaft über Wasser halten und somit sein politisches Überleben sichern. Die Integration mit Russland bringt ihm günstige Energie, Handelspräferenzen und den Machterhalt des Regimes. Im Gegen- 
zug tritt Belarus Teile seiner Souveränität an Russland ab. Da sich der wirtschaftliche Niedergang aber trotz der russischen Subventionen weiter fortsetzt, bleibt das Regime Lukaschenka weiter angreifbar und ist damit gut von Moskau zu kontrollieren.

\section{Vorbild Belarus}

Mit Belarus hatte die Integrationspolitik Putins im postsowjetischen Raum ihren Anfang genommen. Der Unionsstaat von Russland und Belarus war 1999 als Vorstufe eines Zusammenschlusses zu einem Staat gegründet worden. Beim russisch-belarussischen Unionsstaat hat die Idee einer ostslawischen Gemeinschaft eine große Rolle gespielt; sie war die Gründungsidee. Der Versuch, die ostslawische Gemeinschaft wieder zu errichten, scheiterte jedoch, weil sich beide Seiten an Vorbildern aus der Vergangenheit orientierten, die ihre Gültigkeit verloren hatten: Die Putin-Führung lehnte die Wiederherstellung von Wirtschaftsbeziehungen nach dem Vorbild der Sowjetunion und auf russische Kosten ab und akzeptierte nicht die von Belarus geforderte Gleichberechtigung beider Staaten. Präsident Lukaschenka wollte weder sein Land als 90. Subjekt der Russischen Föderation anschließen noch mit Russland eine Art östliche EU aufbauen. So blieb der Unionsstaat eine Zollunion mit sicherheitspolitischen Komponenten wie der gemeinsamen Luftabwehr. Die weitgehend virtuelle Integrationspolitik sicherte das wirtschaftliche Überleben des Regimes Lukaschenka: Mit einer Unterbrechung von 2007 bis 2010 alimentierte Russland Belarus jährlich mit einer Summe, die etwa einem Sechstel des belarussischen BIP entsprach. Die Fassade des Unionsstaates ist bis heute bestehen geblieben, weil beide Seiten profitieren. Belarus ist wirtschaftlich von Russland abhängig, international isoliert und befindet sich damit im Einflussbereich Russlands.

\section{Ukraine als Problemfall}

In der Politik gegenüber der Ukraine hat die Idee der ostslawischen Gemeinschaft ebenfalls eine Rolle gespielt, wenn sie auch nicht so stark artikuliert wurde wie im Verhältnis zu Belarus. Der Streit mit Russland um die Bestrebungen der Ukraine, der transatlantischen Gemeinschaft (NATO) beizutreten, hat das bilaterale Verhältnis 2007/2008 erheblich belastet. Der Widerstand Russlands gegen einen Beitritt der Ukraine zur NATO wurde mit den »besonderen Beziehungen" begründet, die sich aus den engen sprachlichen, religiösen und kulturellen Verflechtungen und der gemeinsamen Vergangenheit in einem Staat herleiteten. Russland gründete 2003 den Einheitlichen Wirtschaftsraum, um die Ukraine einzubinden, wenn dies auch nicht unter dem Vorzeichen einer ostslawischen Einigung geschah. Russland blockierte die Integration indes selbst, weil es politische Zugeständnisse forderte, zu denen die Ukraine nicht bereit war. Die Orange Revolution 2004 wurde von der russischen Führung als geopolitische Niederlage und Ausdehnung des westlichen Einflusses interpretiert. Zudem wuchs die Furcht vor einem Übersprungeffekt, der eine Gefahr für das eigene autoritäre Regime darstellen könnte. Putin warnte vor einer "Ukrainisierung" des politischen Systems in Russland. Es wurden propagandistisch, als vorgebliche Bedrohung Russlands "Feinde« im In- und Ausland aufgebaut, unter denen die »orange " Führung in der Ukraine - trotz aller ostslawischer Gemeinsamkeit - ganz oben rangierte. Dies sollte die russische Gesellschaft und die Macht Putins stabilisieren. Der Widerstand gegen einen Systemwechsel wurde zur obersten Maxime der Innenund Außenpolitik. Die GUS musste als russische Interessenssphäre und als Puffer gegen westlichen Einfluss verteidigt werden. Mit dem Machtwechsel in Kiew 2010 und dem Amtsantritt des als prorussisch geltenden Präsidenten Janukowytsch sah Russland neue Chancen, die Ukraine in seine Integrationsprojekte einzubinden.

\section{Die Eurasische Integration}

Die russische Führung beschleunigt seit 2010 ihre Integrationsaktivitäten im postsowjetischen Raum, die wurden zur Schlüsselausrichtung der Außenpolitik der Russischen Föderation erklärt. Moskau fühlte sich durch die Europäische Union herausgefordert, deren östliche Partnerschaft als Konkurrenz um die Gunst der westlichen GUS-Staaten gesehen wird. 2010 trat die Zollunion von Russland, Belarus und Kasachstan in Kraft. 2012 erklärte Moskau den Einheitlichen Wirtschaftsraum (gemeinsamer Binnenmarkt) zur Wirklichkeit - allerdings mit dem Manko, dass die Ukraine nicht betrat. Der Einheitliche Wirtschaftsraum (EWR) soll nach dem Willen Putins 2015 seine Vollendung in der Eurasischen Union finden - einem Gegenentwurf zur EU. Anders als bei der EU handelt es sich bei diesen Vorhaben aber vorrangig um ein politisches Projekt, das von einem einzelnen Staat dominiert wird. Der supranationale Zusammenschluss soll die Nachbarn über seine russisch dominierten Institutionen an Russland binden.

Die Politik von Zuckerbrot und Peitsche - die bei Belarus zumindest teilweise erfolgreich war - wird von Moskau nun auch bei der Ukraine eingesetzt. Nachdem die ukrainische -Führung unter Janukowytsch der EUAssoziierung (vorerst) eine Absage erteilt hatte, eilte die russische Führung ihrem Kollegen mit einem 15-Milliarden-Kredit zu Hilfe und senkte den Gaspreis um ein Drittel. Putin hat wiederholt versichert, dass der Kredit ohne Bedingungen gewährt worden sei. Allerdings machte der Präsident im Dezember 2013 bei einer Pressekonferenz 
deutlich, dass die Vergünstigungen für Gas nur zeitweilig seien: Russland erwarte langfristige Entscheidungen, um den Preis zu halten. Russland strebt ein gemeinsames Konsortium zur Verwaltung der Exportpipelines an. Die Agentur ITAR-TASS meldete, die Verhandlungen mit »Gazprom« über den Verkauf eines Aktienpaketes des ukrainischen Pipelinebetreibers sollten 2014 beginnen.

Russland und einige ukrainische Oligarchen waren die beiden wichtigsten Machtsäulen des nun gestürzten Präsidenten Janukowytsch. Dass Russland mit dem Kredit nicht wie behauptet dem ukrainischen Volk helfen wollte, sondern erstrangig das politische Überleben der Janukowytsch-Führung zum Ziel hatte, wurde Ende Januar deutlich, als Putin nach der ersten Zahlung von drei Milliarden US-Dollar die nächste Kredittranche auf Eis legte. Obwohl sich Janukowytsch nun im russischen Exil befindet, sieht Moskau in ihm weiterhin den legitimen Präsidenten der Ukraine. Denn von der neuen Regierung in Kiew ist eine Teilnahme an Putins eurasischen Integrationsprojekten kaum zu erwarten.

\section{Konservative Präsidentenberater}

Einer der Vordenker dieser Integrationsprojekte ist der Berater des russischen Präsidenten für regionale Wirtschaftsintegration Sergej Glasjew. Die Assoziierung mit der EU habe nach Ansicht Glasjews allein das Ziel, die Ukraine von Russland loszureißen und den Beitritt Kiews zur Zollunion zu verhindern. Jetzt entfache der Westen das Feuer, "um eine Notbremse zu schaffen, die die Ukraine nicht zu uns lässt, zu Russland“, sagte der Professor im Interview mit dem Fernsehsender "Doschd». Die Ukraine verliere im Freihandel mit der EU zwei Milliarden US-Dollar jährlich wegen der steigenden Importe aus Europa, die Integration bringe nur die Verpflichtung, die europäischen Direktiven umzusetzen: "Die Ukraine wird einfach zu einer Kolonie der Europäischen Union ohne das Recht einer selbstständigen Wirtschafts- und Außenpolitik«, warnte Glasjew. Der Beitritt zu Zollunion hingegen garantiere ein Plus von zehn Milliarden US-Dollar jährlich und ein anhaltendes Wirtschaftswachstum. Mit Blick auf die Westukraine sagte Glasjew: „Welche Integration brauchen sie - die, die damals in den Jahren 1941-42 bestand? Das war auch eine Eurointegration", womit der Präsidentenberater die EU-Integration mit der nazi-deutschen Besatzung gleichsetzte.

In einem Aufsatz verglich der Präsidentenberater die Ukraine mit einem an Schizophrenie erkrankten Patienten, der der imperialen Politik der USA und Polens zum Opfer gefallen sei. Die Polen wollten die Ukraine wie in der Zwischenkriegszeit wieder an ihr Territorium anschließen. Die Heilung könne nur der "Doktor« Putin bringen, der Beitritt zur Zollunion beschere der Ukraine ein Wirtschafswachstum bis zu 9\% bis 2030, schrieb Glasjew in dem Beitrag auf seiner persönlichen Webseite. „Die Ukraine ist und bleibt das historische und geistige Zentrum der Russischen Welt und Kiew die Mutter der russischen Städte. Sie ist für die EU eine Versuchung und kann zur Katastrophe werden, wie es schon mehrfach bei den vergangen Versuchen der zwangsweisen Eurointegration Russlands geschehen ist."

\section{Fehlende Nachhaltigkeit russischer Außenpolitik}

Bisher strebte die Putin-Führung nicht die Annexion der Nachbarstaaten an. Vielmehr sollen sie formal unabhängig, aber von Moskau wirtschaftlich und politisch kontrolliert werden. Ob diese Linie jetzt im Fall der Krim überschritten wird, bleibt abzuwarten. Einerseits erklärte Putin, Russland beabsichtige nicht, die Krim in die Russische Föderation einzugliedern. Anderseits berief er sich auf das Recht der Völker zur Selbstbestimmung: »Aber die Bürger selbst, die in bestimmten Territorien wohnen, haben das Recht, ihr eigenes Schicksal zu bestimmen", sagte der russische Präsident nach einem Bericht der Zeitung "RBK daily«.

In seinem als »Sphäre privilegierter Interessen« definierten Hegemonialbereich duldet Moskau keinen westlichen Einfluss - da er auch als Gefahr für das eigene autoritäre Regime wahrgenommen wird. Die Ukraine und Belarus wie auch andere GUS-Staaten bleiben wegen ihrer wirtschaftlichen Abhängigkeit im russischen Einflussbereich. Doch Moskau verfolgt keine stringente außenpolitische Linie. Die Außenpolitik Russlands ist widersprüchlich, weil geopolitische und wirtschaftliche Interessen kollidieren. Einerseits sollen nationale Wirtschaftsinteressen durchgesetzt werden, andererseits fällt Russland in seine Sponsorenrolle zurück, um geopolitisch motivierte Integrationsprojekte voranzutreiben. Moskau verfügt über kein Integrationsmodell, das der Konkurrenz der EU standhalten könnte. Das russische Integrationskonzept beruht auf dem Austausch politischer Loyalität gegen wirtschaftliche Präferenzen. Die außenpolitischen Instrumente - wirtschaftliche und militärische Druckmittel sowie finanzielle Hilfe - sind nicht zukunftsfähig. Wenn Russland kein alternatives Modell entwickelt, bleibt die Integration für Belarus und die Ukraine eine Zwangsjacke, aus der sie sich befreien, sobald sie dazu wirtschaftlich in der Lage sind. Ebenso könnten sich Belarus und die Ukraine aus der Einflusssphäre lösen, wenn Russland es sich infolge einer Wirtschaftskrise nicht mehr leisten kann, die Nachbarn mit günstigen Rohstoffen und anderen Präferenzen zu alimentieren.

Informationen über die Autorin und einen Lesetipp finden Sie auf der nächsten Seite. 


\section{Über die Autorin}

Dr. phil. Susanne Spahn lebt als freie Journalistin, Historikerin und Politologin in Berlin. Sie ist auf Politik, Wirtschaft und Geschichte Osteuropas spezialisiert. Kürzlich erschienen von ihr: „Warum die ostslawische Gemeinschaft der Russen, Belarussen und Ukrainer gescheitert ist«, in: Gasior, Agnieszka, Karl, Lars, Troebst, Stefan (Hg.): PostPanslavismus. Slavizität, Slavische Idee und Antislavismus im 20. und 21. Jahrhundert. Göttingen 2014, S. $258-278$. Ebenso: „Kritik bei der Symphonie unerwünscht. Staat, Russisch-Orthodoxe Kirche und Meinungsfreiheit in Russland«, in: Bökenkamp, Gérard (Hg.): Meinungsfreiheit und Religion. Berlin 2013, S. 167-191. Ihre Dissertation "Staatliche Unabhängigkeit - das Ende der ostslawischen Gemeinschaft? Die Außenpolitik Russlands gegenüber der Ukraine und Belarus seit 1991« wurde 2011 in Hamburg publiziert.

Lesetipp

Abfall der Ukraine wäre für Russland ein Schnitt ins Fleisch, Interview mit dem Osteuropa-Historiker Andreas Kappeler, in: Wiener Zeitung, 5.11.2013

\section{ANALYSE}

\section{Militärische Implikationen der Krim-Krise}

Margarete Klein/ Kristian Pester, Berlin

$\mathrm{D}$ ie Krim-Krise offenbart eine neue Qualität der russischen Außenpolitik. Rechtfertigte der Kreml den Einsatz seiner Soldaten im Georgienkrieg 2008 noch mit dem Angriff auf die GUS-Friedenstruppen, entsandte er die Streitkräfte diesmal vorsorglich zur Sicherung politischer Interessen in die von ihm beanspruchte Einflusszone. Die Aggressivität des russischen Militäreinsatzes steht dabei im Kontrast zur bisherigen Zurückhaltung der ukrainischen Seite. Zwar wurde die landesweite Mobilmachung verkündet; bislang versuchen die ukrainischen Soldaten aber nicht, sich gewaltsam aus den umstellten Kasernen zu befreien. Das wirft die Frage auf, in welchem Zustand sich die ukrainischen Streitkräfte befinden und welche Perspektiven sich daraus für den Konflikt zwischen Russland und der Ukraine ergeben.

\section{Militärischer Kräftevergleich}

In Bezug auf die quantitativen Parameter ist die russische Seite der Ukraine um ein vielfaches überlegen. So dienen Moskau insgesamt 6,5-mal mehr Soldaten als Kiew. Hinsichtlich Ausrüstung und Bewaffnung fällt das Ungleichgewicht ähnlich gravierend aus (siehe Tabelle 1 auf S. 6). Konzentriert man sich hingegen auf die Krise auf der Krim, erscheint es sinnvoller, das lokale Kräfteverhältnis zu bewerten. Derzeit ist davon auszugehen, dass 13.000-15.000 russische Soldaten der Schwarzmeerflotte auf der Halbinsel stationiert sind; hinzu kommen die Verstärkungen mit spezialisier- ten Kräften, wie Marineinfanterie und Luftlandetruppen. Die Angaben zu diesem Kontingent schwanken beträchtlich: Berichten zufolge sind es zwischen 2.000 und 15.000. Gleichzeitig ist völlig unklar, wie viele paramilitärische Verbände vor Ort sind und wem diese überhaupt unterstehen. Sie helfen dabei, die ukrainischen Militäranlagen zu bewachen und wichtige Verkehrsadern zu kontrollieren. Sollte die gegenwärtige Krise in einen bewaffneten Konflikt münden, sind darüber hinaus sämtliche Truppenteile des westlichen und südlichen Militärbezirks Russlands in die Berechnung einzubeziehen. Deren verfügbare Waffensysteme überwiegen nicht nur nominal die der gesamten ukrainischen Armee. Sie wären bei einer Offensive zudem logistisch in der Lage, ein begrenztes Territorium der Ostukraine $\mathrm{zu}$ besetzen und zu halten.

Auch in qualitativer Hinsicht sind die russischen Streitkräfte besser aufgestellt. Dies liegt vor allem an den Ergebnissen eines 2008 initiierten umfassenden Reformprogramms. In dessen Verlauf wurden die Landstreitkräfte von einer schwerfälligen Divisionsgliederung in eine mobilere und flexiblere Einsatzstruktur überführt sowie der Trainingszustand im Rahmen zahlreicher Übungen gesteigert. Auch im Bereich der Professionalisierung von Mannschaften und Unteroffizieren sind erste Erfolge zu verzeichnen. Andererseits konnte die veraltete Ausrüstung und Bewaffnung bislang nur in begrenztem Umfang erneuert werden. 


\section{Verteidigungspolitische Kontextfaktoren}

Trotz dieser zwiespältigen Bilanz ist aber festzustellen: Die bisherigen Versuche Kiews, das Militär auf ähnliche Weise umzugestalten, sind im Vergleich weitaus weniger erfolgreich verlaufen. Eine maßgebliche Ursache hierfür ist die chronische Unterfinanzierung der ukrainischen Armee. Selbst wenn man berücksichtigt, dass Russland ein umfangreiches Nukleararsenal aufrechterhält und weitaus mehr Soldaten besitzt, steht der ukrainische Verteidigungsetat in keinem Verhältnis zum Umfang und Auftrag der Streitkräfte. Er stagniert auf sehr niedrigem Niveau, während die russischen Verteidigungsausgaben in den letzten Jahren massiv erhöht wurden. (siehe Tabelle 2 auf S. 6 und Grafik 1 auf S. 7).

Darüber hinaus belasteten in der Ukraine die wechselhaften politischen Rahmenbedingungen in der Vergangenheit sowohl eine kohärente Zielsetzung als auch die Umsetzung von Reformen. Seit der »orangen Revolution« im Dezember 2004 amtierten acht Verteidigungsminister. Die militärstrategische Ausrichtung der Streit- kräfte pendelte unterdessen zwischen einer westlichen Orientierung, einer neutralen Positionierung und der stärkeren Kooperation mit Russland.

\section{Der Militäreinsatz bleibt eine Option}

Angesichts dieser Situation ist offensichtlich, dass die ukrainischen Streitkräfte nur äußerst begrenzt in der Lage sind, den gegenwärtigen russischen Militäreinsatzes auf der Krim zurückzudrängen. Im Falle eines lokalen oder sich sogar regional ausweitenden bewaffneten Schlagabtausches wären sie der russischen Seite sicher unterlegen. Vor dem Hintergrund der atemberaubenden Eskalationsdynamik und der Tatsache, dass die verhängten und angedrohten politischen und wirtschaftlichen Sanktionen bislang kein Einlenken Moskaus bewirkten, könnten militärische Optionen in der europäischen und transatlantischen Diskussion künftig eine größere Rolle spielen. Bereits in den vergangenen Tagen ergriff die NATO erste Maßnahmen zur Rückversicherung ihrer östlichen Mitgliedstaaten.

\section{Über die Autoren}

Dr. Margarete Klein ist wissenschaftliche Mitarbeiterin in der Forschungsgruppe Osteuropa und Eurasien der Stiftung Wissenschaft und Politik (SWP) in Berlin. Sie arbeitet dort zu Fragen der russischen Außen-, Sicherheits- und Militärpolitik.

Kristian Pester, Major i.G., Dipl.-Päd., ist Wissenschaftlicher Mitarbeiter der Forschungsgruppe: Osteuropa und Eurasien <http://www.swp-berlin.org/de/forschungsgruppen/osteuropa-und-eurasien.html>, Stiftung Wissenschaft und Politik.

Tabelle 1: Kräftevergleich der russischen und ukrainischen Streitkräfte

\begin{tabular}{|l|r|r|}
\hline & Russland & Ukraine \\
\hline $\begin{array}{l}\text { Truppenstärke } \\
\text { darunter spezialisierte Kräfte }\end{array}$ & 845.000 & 129.950 \\
$\begin{array}{l}\text { Bewaftlandetruppen, Marineinfanterie) } \\
\text { (u. a. Innenministerium) }\end{array}$ & 55.000 & 9.000 \\
Kampfpanzer & 519.000 & 94.000 \\
Bomber & 2550 & 1110 \\
Kampfjets & 141 & 0 \\
U-Boote & 580 & 126 \\
Fregatten, Kreuzer und Zerstörer & 64 & 1 \\
Landungsschiffe & 42 & 1 \\
\hline
\end{tabular}

Quelle: Eigene Darstellung basierend auf den Daten von International Institute of Strategic Studies, Military Balance 2013.

Tabelle 2: Russischer und ukrainischer Verteidigungsetat (in Mrd. Euro)

\begin{tabular}{|l|r|r|r|r|r|}
\hline & 2009 & 2010 & 2011 & 2012 & 2013 \\
Russland & 46,35 & 40,57 & 41,29 & 44,32 & 49,74 \\
\hline Ukraine & 1,05 & 1,18 & 1,29 & 1,54 & 1,40 \\
\hline
\end{tabular}

Quelle: Eigene Darstellung basierend auf den Daten von Jane's Military and Security Intelligence Center (IHS), 2014. 
Grafik 1: Russisches und ukrainisches Verteidigungsbudget (in Mrd. EUR)

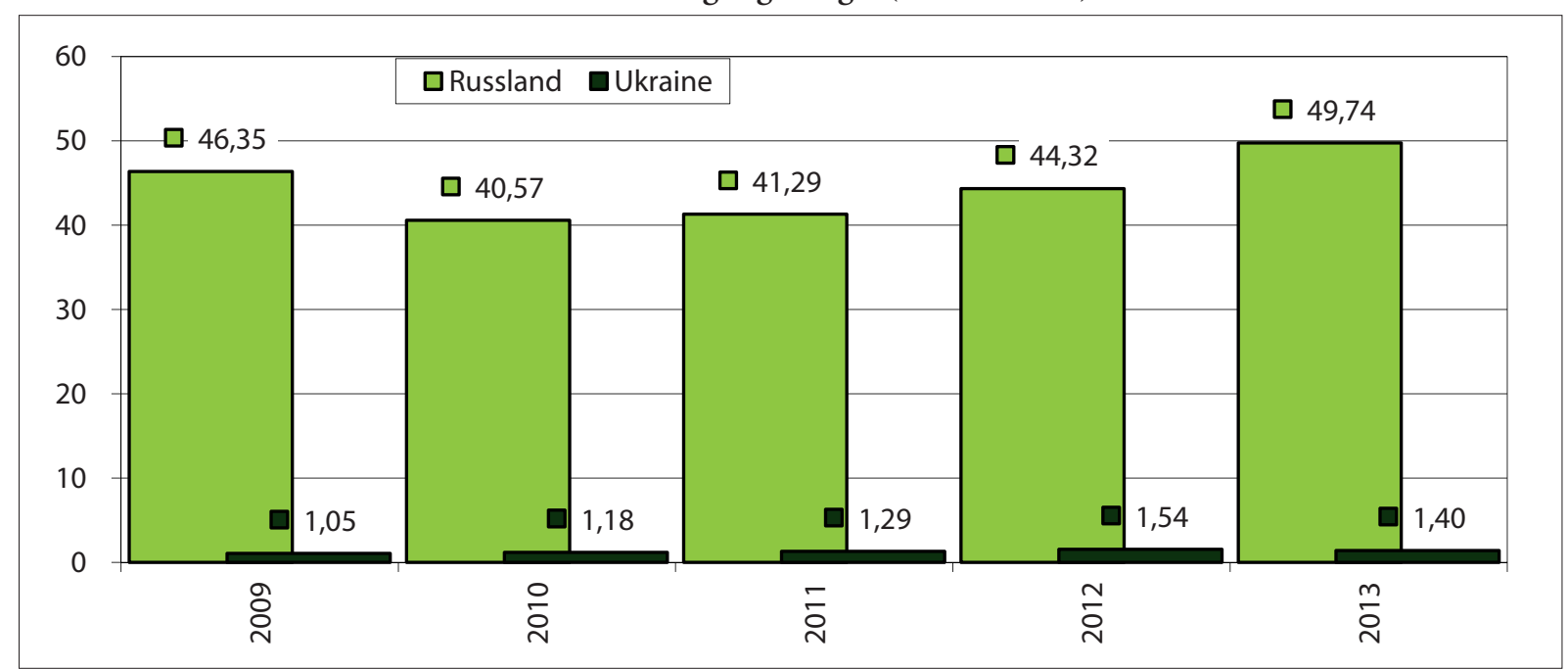

Quelle: Eigene Darstellung basierend auf den Daten von Jane's Military and Security Intelligence Center (IHS), 2014.

\section{UMFRAGE}

\section{Die russischen Streitkräfte in Umfragen}

Grafik 2: Wie würden Sie den aktuellen Zustand der russischen Armee bewerten?

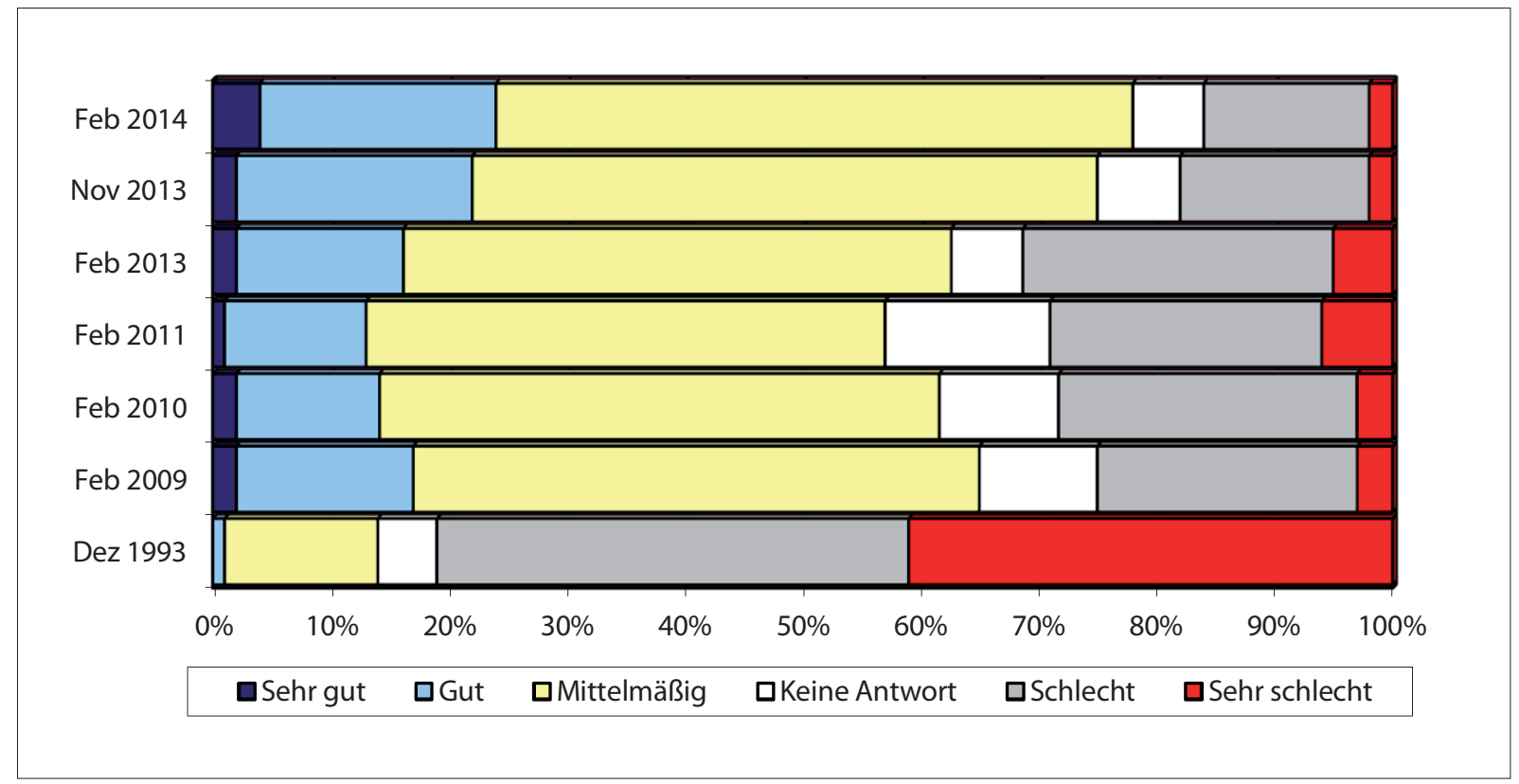

Quelle: Umfragen des WZIOM vom 15.-16. Februar 2014, N = 1603. Veröffentlicht am 4. März 2014 unter: $<$ http://wciom.ru/index.php?id=459\&uid=114729> 
Grafik 3: Besteht aktuell Kriegsgefahr für Russland von Seiten anderer Länder?

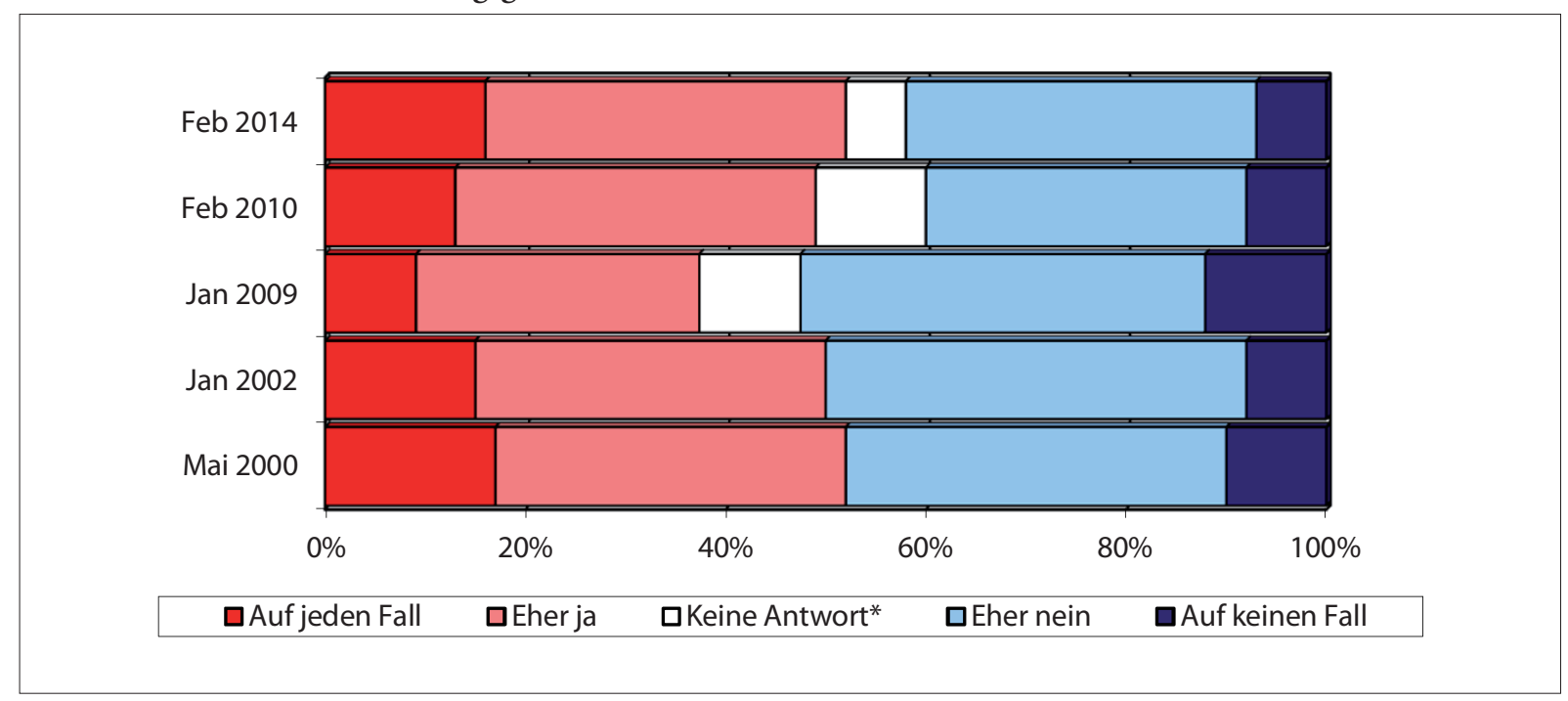

* Bis 2009 war diese Antwortoption nicht vorgesehen

Quelle: Umfragen des WZIOM vom 15.-16. Februar 2014, N = 1603. Veröffentlicht am 4. März 2014 unter:

<http://wciom.ru/index.php?id=459\&uid=114729>

\section{Der Krim-Krieg findet nicht statt}

\section{Strategie und Taktik einer zielgerichteten Eskalation und eine mögliche Konfliktlösung}

Benno Ennker, Konstanz

\section{"Großer Plan« oder Panikreaktion?}

Der Konflikt um die Krim, den Wladimir Putin seit Wochen von einer Eskalationsstufe zur nächsten treibt, ist eine Reaktion auf die EU-Assoziierung und den Sturz des Janukowytsch-Regimes. Um die Interessen und Motive der russischen Führung genauer zu erfassen, muss ihr strategischer und taktischer Kontext betrachtet werden. Den Hintergrund bildet eine mit der 3. Putinschen Präsidentschaft begonnene ausdrücklich anti-westliche Ausrichtung der russischen Innen- und Außenpolitik. Putin hat diese bei seinen großen Pressekonferenzen Ende 2012 und Ende 2013 unterstrichen, und sie hat ihren dokumentarischen Ausdruck in der "Außenpolitischen Konzeption« erhalten, wie sie Putin im Februar 2013 unterschrieben und dem Sicherheitsrat der Russischen Föderation präsentiert hat. Dort wird für Russland - auch ideologisch und propagandistisch - eine strategische Positionierung als Gegenpart des Westens festgeschrieben, in der konservativ-autoritäre Werte und die Ordnung des Machtstaates als weltweites Beispiel dem "moralischen Verfall« des Westens durch libertäre Gesetzgebung gegenübergestellt wird. Dabei wird nun neben den USA auch die Europäische Union als Gegner wahrgenommen. Russland hat die "Europäische Nachbarschaftspolitik«als "Östliche Partnerschaft» (seit 2009), die sich an die Ukraine, Weißrussland und Moldawien, sowie an Armenien, Aserbaidschan und Georgien richtet, immer als feindliches Eindringen in den von ihm dominierten geopolitischen Raum der postsowjetischen Staaten betrachtet. Der war nach dem Georgien-Krieg 2008 durch den damaligen Präsidenten Dmitrij Medwedew als russische Interessensphäre deklariert worden.

Im Oktober 2011 veröffentlichte Putin seinen Plan für eine »Eurasische Union«, die den Ausgangspunkt für eine politische Integration bieten solle. Als Mitglieder oder Anwärter firmieren neben Russland und Belarus auch Kasachstan, seit kurzem auch Armenien, das sich, nachdem von Russland erheblicher wirtschaftlicher und 
politischer Druck ausgeübt wurde, auf den Status als Beobachter-Staat und Kandidat für den Beitritt festgelegt hat. Für Russland ist die Ukraine nicht nur in wirtschaftlicher und geostrategischer Hinsicht das Herzstück dieser neuen Union. Deswegen ringt Russland um dieses Land unter Einsatz aller ökonomischen, politischen und ideologischen Instrumente. Das imperiale Projekt kann als das einzige zentrale strategische Projekt von Putins dritter Präsidentschaft angesehen werden, mit dem er das ganze innenpolitische Prestige seiner Person verbindet, und das das Trauma der Auflösung der Sowjetunion als "geopolitischer Katastrophe« heilen soll. Für den Kreml stehen diese geostrategische Dimensionen der russischen Außenpolitik auf dem Spiel, seit seine Integrationsbemühungen mit der Krise und dann dem Fall des Janukowytsch-Regime einen Rückschlag erlitten.

Man kann das russische Vorgehen, das so einseitig auf politische und militärische Mittel zurückgreift und auf kurzfristige Erfolge abzielt, als eine Flucht nach vorn betrachten, die offensichtlich allein nach den Logiken von Militär- und Geheimdienstoperationen erfolgt und dabei nicht auf augenblickliche Kollateralschäden und längerfristige Folgeschäden politischer Art Rücksicht nimmt. Die politischen und militärischen Mittel, die als Reaktion eingesetzt wurden, zielen auf kurzfristige, durch unmittelbaren Gewalt und Druck erzeugte Wirkungen, in der Hoffnung, den gesamten Prozess in der Ukraine sowie die "geopolitische Niederlage« dort zurückzudrehen, die Ukraine unter Androhung einer Spaltung auf das Gleis der Ost-Integration zu zwingen. Das russische Vorgehen wurde unter Bedingungen eines großen Konsenses der politischen Elite und des größten Teils der Gesellschaft möglich, weil Putin damit auf prinzipielle strategische Dispositionen zurückgriff, die seit langem vorbereitet und seit kurzem zugespitzt worden sind.

\section{Fehlkalkulationen und Schwächen der russischen Aggression}

Die Fehlkalkulationen bzw. Schwächen des aggressiven russischen Vorgehens lassen sich in einigen Punkten zusammenfassen:

- Die Begründungen (Gefährdung der Russen in der Ukraine) und die Camouflage der militärischen Intervention sind für die Weltöffentlichkeit mehr als durchschaubar;

- Im Unterschied zur Georgien-Krise findet sich auf Seiten der EU eine einheitliche Meinungs- und Entscheidungsbildung; ähnliches gilt für deren Verhältnis zur Haltung der USA, wenn diese auch keine "Hyperaktivität« an den Tag legen.

- In der Ukraine ist bisher eine Einheitlichkeit der sich neu bildenden politischen Elite zustande gekommen, die unter dem Druck der Gefährdung des Staates - über die Regierungs-Koalition hinaus - fast sämtliche Teile des Parlaments umfasst.

- Dabei konnte auch der größere Teil der wirtschaftlichen Elite, nicht zuletzt die wichtigsten Oligarchen, auf eine Loyalität zum ukrainischen Staat verpflichtet und außerdem die Institutionen des Staates zunehmend stabilisiert werden.

- Ob die angeblich "prorussischen« Regionen im Südosten des Landes den separatistischen Weg gehen wollen, der auf der Krim gewaltsam eingeschlagen worden ist, hängt sicher davon ab, welche Integrationsschritte die neue Regierung vorsieht und welche Garantien für die Kultur und Repräsentation der russischen Minderheit im Land gegeben werden.

- Die EU zeigt zunehmend Bewusstsein dafür, dass die Demokratie in der Ukraine nur dann eine Chance hat, wenn sie kurzfristig durch Wohlfahrtserfahrungen auf Basis einer ökonomischen Stabilisierung gestützt wird.

Putins Risiken in seinem Vabanquespiel steigen von Tag zu Tag: Die Beunruhigung unter den Nachbarstaaten über den Grenz-Revisionismus Russlands unter Hinweis auf den Schutz russischer Minderheiten dürfte zunehmen, da sie selbst vielfach einen russischen Bevölkerungsanteil von 10 bis $25 \%$ haben - zumal in Grenzregionen. Damit könnte die Bereitschaft, an Putins Eurasischer Union mitzuwirken, fraglich werden. Am Ort des Geschehens, auf der Krim, ist geradezu ein "totalitärer Raum" konstituiert worden, denn dort hat sich unter Russlands Protektion ein gefährlicher, z. T. bewaffneter Mob breit gemacht, der sowohl das Parlament als auch alle widerspruchsbereiten Einwohner sowie ausländische Journalisten und OSZE-Beobachter bedroht und auf Konfrontation mit den ukrainischen Militäreinheiten aus ist. Sollte Putin die Aggression nicht einstellen, würden wirtschaftliche Sanktionen sowohl die Angehörigen der Elite Russlands als auch seine wirtschaftlichen Strukturen treffen. Ob unter solchem Druck die wirtschaftliche und politische Elite unverbrüchlich zu einem Abenteurer hält, ist ebenfalls fraglich. Es wird darauf ankommen, dass diese Sanktionen einen derartigen Druck erzeugen können, dass das »Abenteuer Ukraine« für die wirtschaftlichen und politischen Eliten Russlands zu heikel wird.

\section{Strategische Ziele für eine Konfliktlösung}

Hauptziel bleibt ohne Zweifel, den Rahmen für demokratische Freiheit für das ukrainische Volk und für die Souveränität und Integrität seines Staates zu gewährleisten. Ob dies in Hinblick auf die Krim auf Dauer durchgesetzt werden kann, bleibt offen. Gegenwärtig dürfen dort "Volksabstimmungen" unter Belagerungszustand und Straßenterror nicht anerkannt werden. Erst wenn die 
Konsolidierung des ukrainische Staates und seiner Demokratie durch freie Neuwahlen, evtl. auch zu einer Verfassunggebenden Versammlung, unter massiver OSZEBeobachtung ermöglicht und erreicht wird, kann eine solche Volksabstimmung unter Bedingungen einer Zivilgesellschaft zugesagt werden. Dies hat zur Voraussetzung, dass die Integrität des Staates in Bezug auf die südöstlichen Regionen garantiert und beachtet wird. Von ukrainischer Seite würde dies wahrscheinlich die Entwicklung eines föderativen Staatsaufbaus verlangen, wie er in den betreffenden Regionen häufig verlangt wird. Da für eine Konfliktlösung - ähnlich wie in dem am 5.3.2014 von Henry Kissinger vorgeschlagenen Modell - die Zustim- mung aller geopolitischen Akteure notwendig ist, verlangt sie von allen Seiten die Einsicht, dass folgende Alternative besteht: Entweder die Ukraine unter diesen Kautelen zu erhalten und zu garantieren und sie ohne militärisches Bündnis zu erhalten, oder sie im Falle einer Abspaltung ihrer südöstlichen Teile zugunsten der Russischen Föderation in die NATO zu integrieren. Bedrohten Ländern wie Georgien und Moldau dürfte dann eine Mitgliedschaft auch nicht mehr verwehrt werden. Zu den produktiven Lösungsansätzen gehört zudem, dass bei einer Einigung eine neue Partnerschaft mit entsprechenden Handelserleichterungen zwischen der EU und der Eurasischen Union in Aussicht gestellt wird.

\section{Über den Autor}

Dr. Benno Ennker, Osteuropa-Historiker und Sozialwissenschaftler; bis vor kurzem wissenschaftlicher Mitarbeiter des Instituts für osteuropäische Geschichte und Landeskunde der Uni Tübingen, lehrt Russische Kultur- und Sozialgeschichte an der Uni St. Gallen $(\mathrm{CH})$. Zuletzt sind von ihm erschienen:

- Russland in Bewegung. Putins alte Ordnung und die neuen Dekabristen. In: Osteuropa 1(2012), S. 41-55.

- Zweierlei Krisen in Russland. Machterosion und Neuorientierung. In: Osteuropa 3(2012), S. 3-20.

- Putin und seine Freunde. Die Elite und die Bruchstellen der Macht. In: Osteuropa 6-8(2012), S. 125-143.

\section{Lesetipps}

- Concept of the Foreign Policy of the Russian Federation. Approved by President of the Russian Federation V. Putin on 12 February 2013 <http://www.mid.ru/brp_4.nsf/0/76389FEC168189ED44257B2E0039B16D>

- Taras Kuzio: Crimea - from playground to battleground, in: Open Democracy. (Russia and beyond), 27.2.2014 <http:/www.opendemocracy.net/od-russia/taras-kuzio/crimea---from-playground-to-battleground>

- „Ukraine: The Russia Factor in Crimea - Ukraine’s `Soft Underbelly»? US Embassy Kyiv, December 17, 2006 <http://wikileaks.org/cable/2006/12/06KYIV4489.html>

- Henry A. Kissinger: How the Ukraine crisis ends,- The Washington Post, March 5, 2014 <http://www.washing tonpost.com/opinions/henry-kissinger-to-settle-the-ukraine-crisis-start-at-the-end/2014/03/05/46dad868-a496-11 e3-8466-d34c451760b9_story.html>

Grafik 4: Würden Sie gegenwärtig den Einsatz russischer Truppen auf dem Territorium der Krim und anderen Regionen der Ukraine befürworten?

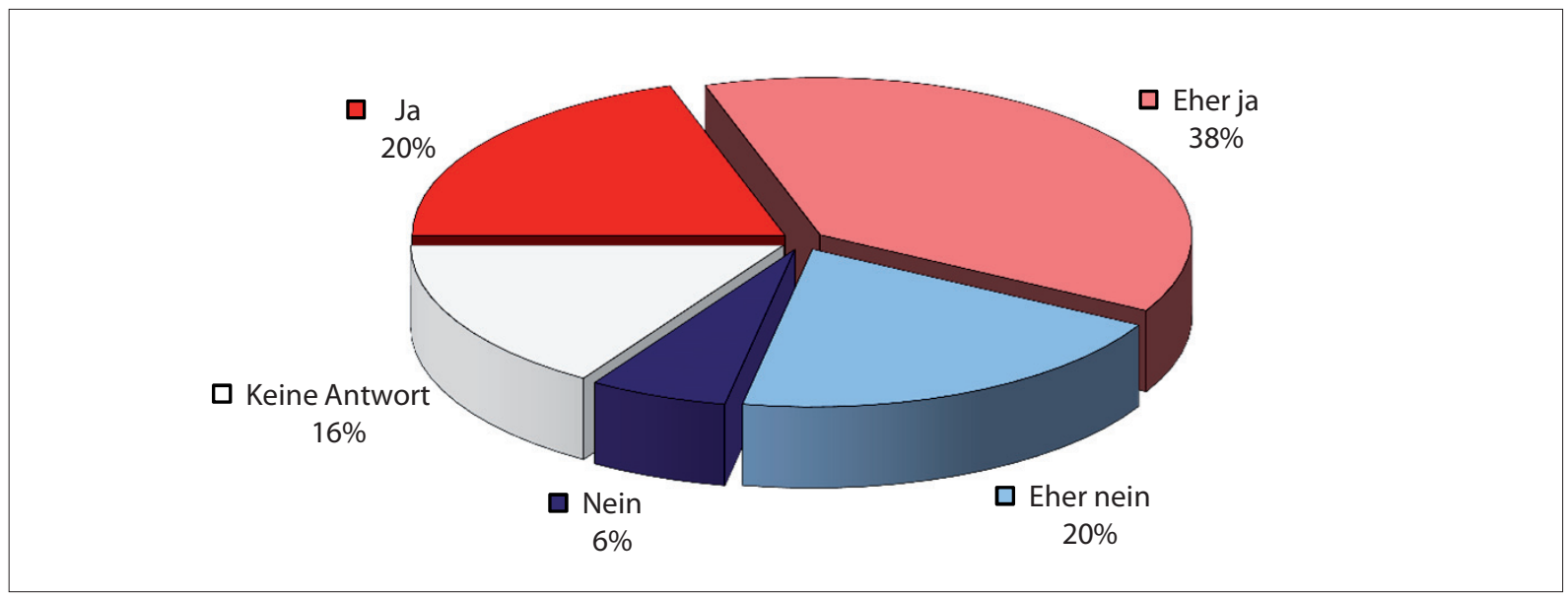

Quelle: Umfragen des Lewada-Zentrums vom 7.-10. März 2014, $N=1603$. Veröffentlicht am 13. März 2014 unter: $<$ http://www.levada.ru/print/13-03-2014/situatsiya-v-ukraine-i-v-krymu> 


\section{Russland und die Ukraine: Wirtschaftsbeziehungen}

Grafik 5: Wirtschaftsleistung und Bevölkerung 2011

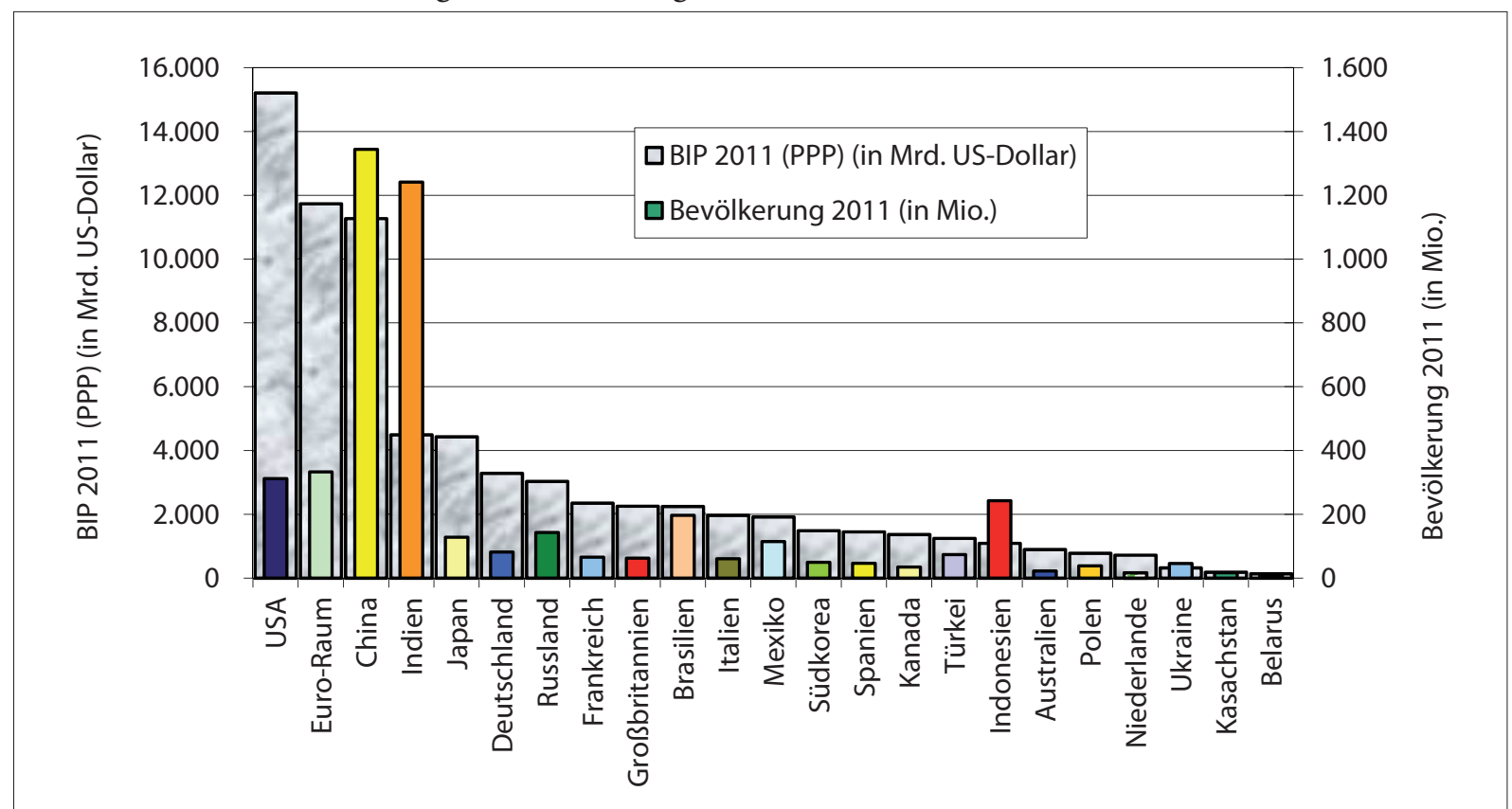

Quelle: Datenbank der Weltbank, Abfrage 15.6.2013 <http://data.worldbank.org/indicator/NY.GNP.MKTP.PP.CD; <http://data. worldbank.org/indicator/SP.POP.TOTL>

Tabelle 3: Wirtschaftsleistung und Bevölkerung 2011

\begin{tabular}{|l|c|c|}
\hline & Bevölkerung 2011 & BIP 2011 (PPP) (in US-Dollar) \\
\hline USA & 311.591 .917 & $15.211 .300 .000 .000,000$ \\
\hline Curo-Raum & 332.930 .875 & $11.735 .720 .183 .945,500$ \\
\hline Indien & 1.344 .130 .000 & $11.270 .762 .968 .567,700$ \\
Japan & 1.241 .491 .960 & $4.492 .862 .147 .205,190$ \\
Deutschland & 127.817 .277 & $4.431 .296 .521 .181,180$ \\
Russland & 81.797 .673 & $3.287 .583 .144 .002,980$ \\
Frankreich & 142.960 .000 & $3.032 .248 .438 .140,030$ \\
Großbritannien & 65.433 .714 & $2.349 .820 .317 .146,860$ \\
Brasilien & 62.744 .081 & $2.255 .941 .657 .442,150$ \\
Italien & 196.655 .014 & $2.245 .843 .052 .105,570$ \\
Mexiko & 60.723 .603 & $1.968 .881 .031 .232,300$ \\
Südkorea & 114.793 .341 & $1.919 .327 .974 .969,280$ \\
Spanien & 49.779 .000 & $1.489 .140 .095 .649,060$ \\
Kanada & 46.174 .601 & $1.451 .689 .457 .283,170$ \\
Türkei & 34.483 .975 & $1.369 .354 .340 .827,710$ \\
Indonesien & 73.639 .596 & $1.247 .331 .834 .370,070$ \\
Australien & 242.325 .638 & $1.091 .447 .849 .335,480$ \\
Polen & 22.323 .900 & $898.947 .026 .369,864$ \\
Niederlande & 38.534 .157 & $780.806 .048 .875,409$ \\
Ukraine & 16.693 .074 & $720.294 .528 .359,096$ \\
Kasachstan & 45.706 .100 & $321.885 .487 .148,141$ \\
Belarus & 16.558 .676 & $186.358 .464 .029,311$ \\
\hline Quelle: Datenbank & 9.473 .000 & $137.002 .187 .210,441$ \\
\hline
\end{tabular}

Quelle: Datenbank der Weltbank, Abfrage 15.6.2013 <http://data.worldbank.org/indicator/NY.GNP.MKTP.PP.CD; <http://data. worldbank.org/indicator/SP.POP.TOTL> 
Tabelle 4: Entwicklung des Bruttoinlandsprodukts der Russischen Föderation (in laufenden Preisen, Mrd. Rubel)

\begin{tabular}{|l|c|c|c|c|c|c|c|c|c|c|}
\hline Jahr & 2013 & 2012 & 2011 & 2010 & 2009 & 2008 & 2007 & 2006 & 2005 & 2004 \\
BIP & $66.689,1$ & $61.810,8$ & $55.644,0$ & $46.308,5$ & $38.807,2$ & $41.276,8$ & $33.247,5$ & $26.917,2$ & $21.609,8$ & $17.027,2$ \\
$\begin{array}{l}\text { In \% zum } \\
\text { Vorjahr }\end{array}$ & $107,89 \%$ & $111,08 \%$ & $120,16 \%$ & $119,33 \%$ & $94,02 \%$ & $124,15 \%$ & $123,52 \%$ & $124,56 \%$ & $126,91 \%$ & \\
\hline
\end{tabular}

Quelle: Rosstat: Nationale Einkommensrechnung <http://www.gks.ru/free_doc/new_site/vvp/tab1.xls>

Tabelle 5: Entwicklung des Bruttoinlandsprodukts der Ukraine (in tatsächlichen Preisen, in Mio. Hrywnja)

\begin{tabular}{|l|c|c|c|c|c|c|c|}
\hline Jahr & 2013 & 2012 & 2011 & 2010 & 2009 & 2008 & 2007 \\
BIP & 1.454 .931 & 1.408 .889 & 1.302 .079 & 1.082 .569 & 913.345 & 948.056 & 720.731 \\
$\begin{array}{l}\text { In \% zum } \\
\text { Vorjahr }\end{array}$ & $103,27 \%$ & $108,20 \%$ & $120,28 \%$ & $118,53 \%$ & $96,34 \%$ & $131,54 \%$ & \\
\hline
\end{tabular}

Quelle: Staatliche Statistikbehörde der Ukraine: Bruttoinlandsprodukt in tatsächlichen Preisen, unter: <http://www.ukrstat.gov.ua/>

Grafik 6: Die führenden 10 Handelspartner Russlands: Exporte (in \% zu den gesamten Exporten)

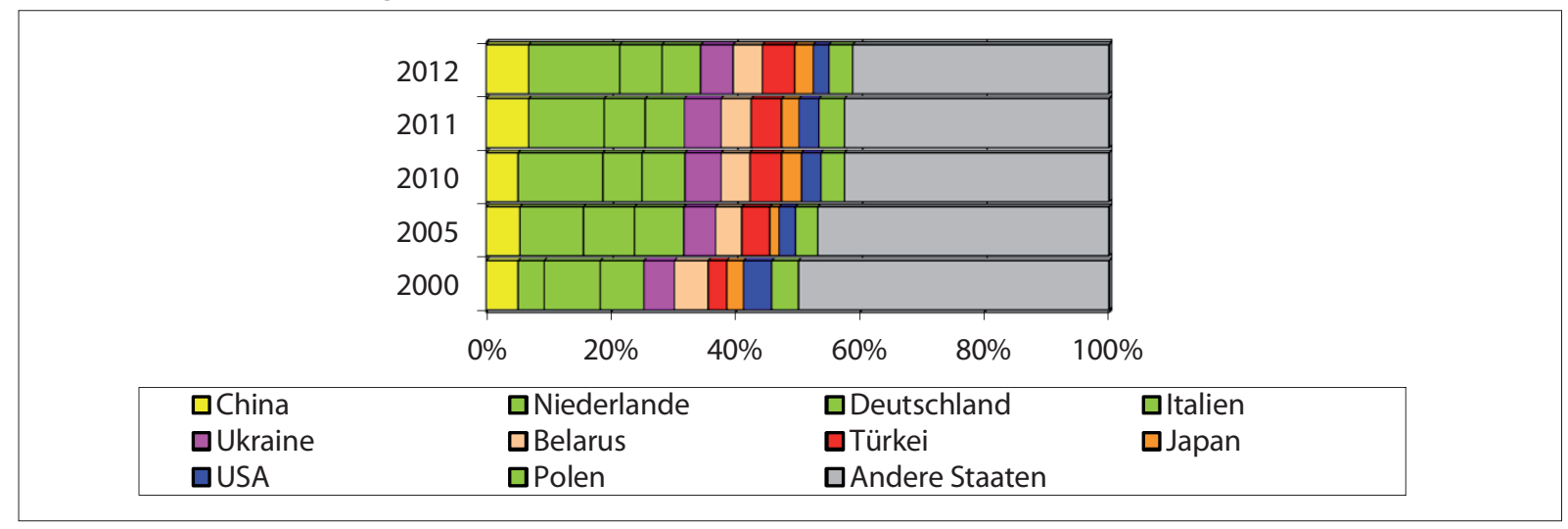

Quelle: Rosstat: Torgowlja w Rossii. 2013, S. 197.

Grafik 7: Die führenden 10 Handelspartner Russlands: Importe (in \% zu den gesamten Importen)

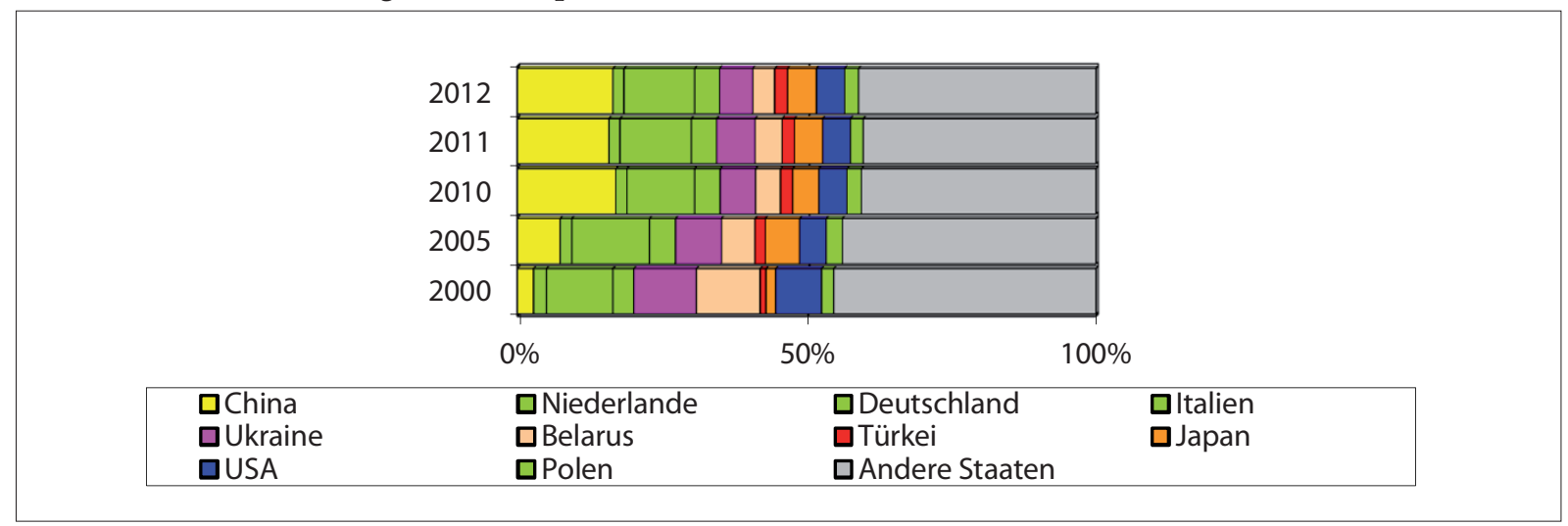

Quelle: Rosstat: Torgowlja w Rossii. 2013, S. 197. 
Tabelle 6: Außenhandel der Russischen Föderation mit zentralen Handelspartnern

\begin{tabular}{|c|c|c|c|c|}
\hline & 2011 & 2012 & & \\
\hline & Mio. US\$ & Mio. US\$ & In \% zu 2011 & $\begin{array}{c}\text { In } \% \text { des } \\
\text { gesamten Ex- } \\
\text { port/Import- } \\
\text { Volumens } \\
\text { mit dem } \\
\text { Handels- } \\
\text { partner }\end{array}$ \\
\hline \multicolumn{5}{|l|}{ Exporte } \\
\hline \multicolumn{5}{|l|}{ Ukraine } \\
\hline Erdöl, Erdölerzeugnisse und verwandte Waren & 20.426 & 17.389 & $85,1 \%$ & $63,9 \%$ \\
\hline Anorganische chemische Erzeugnisse & 1.201 & 1.050 & $87,4 \%$ & $3,9 \%$ \\
\hline Schwarzmetalle & 1.200 & 1.044 & $87,0 \%$ & $3,8 \%$ \\
\hline $\begin{array}{l}\text { Atomreaktoren, Kessel, Apparaturen und mechanische } \\
\text { Vorrichtungen }\end{array}$ & 1.301 & 1.275 & $98,0 \%$ & $4,7 \%$ \\
\hline \multicolumn{5}{|l|}{ Belarus } \\
\hline Erdöl, Erdölerzeugnisse und verwandte Waren & 16.472 & 17.708 & $107,5 \%$ & $71,3 \%$ \\
\hline Schwarzmetalle & 1.833 & 1.086 & $59,2 \%$ & $4,4 \%$ \\
\hline $\begin{array}{l}\text { Atomreaktoren, Kessel, Apparaturen und mechanische } \\
\text { Vorrichtungen }\end{array}$ & 838 & 684 & $81,6 \%$ & $2,8 \%$ \\
\hline Elektrogeräte und Apparaturen und deren Teile & 556 & 515 & $92,6 \%$ & $2,1 \%$ \\
\hline \multicolumn{5}{|l|}{ Kasachstan } \\
\hline Erdöl, Erdölerzeugnisse und verwandte Waren & 4.524 & 4.653 & $102,9 \%$ & $30,3 \%$ \\
\hline Schwarzmetalle & 911 & 912 & $100,1 \%$ & $5,9 \%$ \\
\hline $\begin{array}{l}\text { Atomreaktoren, Kessel, Apparaturen und mechanische } \\
\text { Vorrichtungen }\end{array}$ & 1.177 & 1.195 & $101,5 \%$ & $7,8 \%$ \\
\hline $\begin{array}{l}\text { Transportfahrzeuge, außer Eisenbahn und Straßenbah- } \\
\text { fahrzeug und deren Teile und Zubehör }\end{array}$ & 604 & 1.032 & $170,9 \%$ & $6,7 \%$ \\
\hline \multicolumn{5}{|l|}{ Importe } \\
\hline \multicolumn{5}{|l|}{ Ukraine } \\
\hline Schwarzmetalle & 2.474 & 2.442 & $98,7 \%$ & $13,6 \%$ \\
\hline $\begin{array}{l}\text { Atomreaktoren, Kessel, Apparaturen und mechanische } \\
\text { Vorrichtungen }\end{array}$ & 2.170 & 2.267 & $104,5 \%$ & $12,6 \%$ \\
\hline Elektrogeräte und Apparaturen und deren Teile & 1.082 & 1.197 & $110,6 \%$ & $6,7 \%$ \\
\hline $\begin{array}{l}\text { Eisenbahnloks oder Straßenbahn-Triebwagen, Fahrzeug } \\
\text { und deren Teile }\end{array}$ & 3.218 & 2.657 & $82,6 \%$ & $14,8 \%$ \\
\hline \multicolumn{5}{|l|}{ Belarus } \\
\hline Milchprodukte, Eier, Hühner, natürlicher Honig & 1.548 & 1.075 & $69,5 \%$ & $8,2 \%$ \\
\hline $\begin{array}{l}\text { Werkzeug, Vorrichtungen, Besteck aus unedlen Metallen } \\
\text { und weiteren Teilen }\end{array}$ & 19 & 1.243 & $\ldots \%$ & $9,5 \%$ \\
\hline $\begin{array}{l}\text { Atomreaktoren, Kessel, Apparaturen und mechanische } \\
\text { Vorrichtungen }\end{array}$ & 1.394 & 2.153 & $154,5 \%$ & $16,4 \%$ \\
\hline $\begin{array}{l}\text { Transportfahrzeuge, außer Eisenbahn und Straßenbah- } \\
\text { fahrzeug und deren Teile und Zubehör }\end{array}$ & 3.837 & 1.479 & $38,6 \%$ & $11,3 \%$ \\
\hline \multicolumn{5}{|l|}{ Kasachstan } \\
\hline Erze, Schlacken, Asche & 2.289 & 1.477 & $64,5 \%$ & $14,9 \%$ \\
\hline Erdöl, Erdölerzeugnisse und verwandte Waren & 1.556 & 1.124 & $72,3 \%$ & $11,3 \%$ \\
\hline $\begin{array}{l}\text { Atomreaktoren, Kessel, Apparaturen und mechanische } \\
\text { Vorrichtungen }\end{array}$ & 347 & 1.459 & $\begin{array}{l}\text { um das } \\
4,2 \text {-fache }\end{array}$ & $14,7 \%$ \\
\hline Elektrogeräte und Apparaturen und deren Teile & 244 & 1.459 & $\begin{array}{l}\text { um das } \\
\text { 6-fache }\end{array}$ & $14,7 \%$ \\
\hline
\end{tabular}

Quelle. Federalnaja Slushba Gosudarstwennoj Statistiki (Rosstat): Torgowlja w Rossii 2013. Statistitscheskij sbornik, Moskwa: Rosstat 2013 <http://www.gks.ru/freedoc/doc2013/torg.rar>, S. 207ff. 
Grafik 8: Die führenden 10 Handelspartner der Ukraine 2013: Exporte (in \% zu den gesamten Exporten)

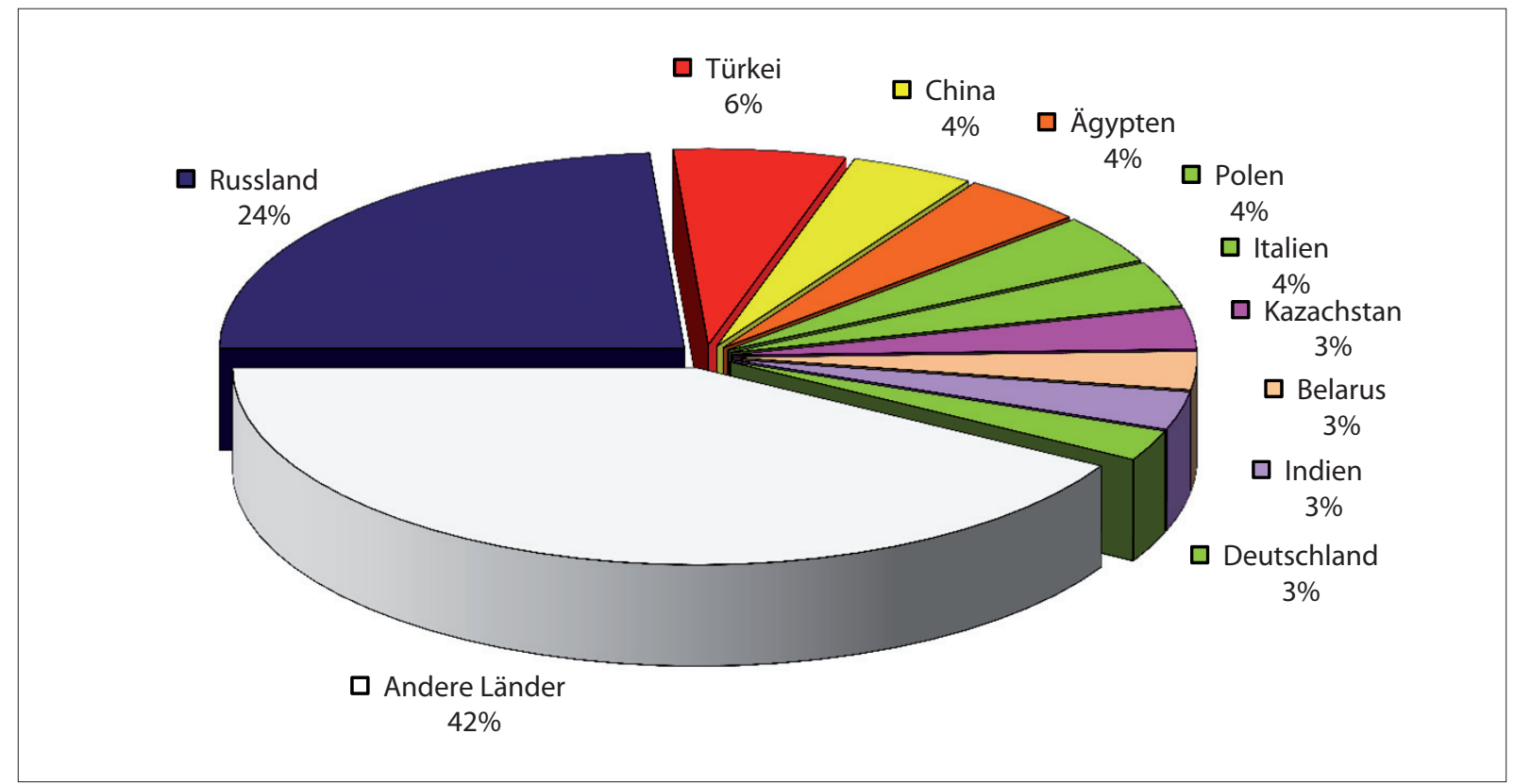

Quelle: Staatliche Statistikbehörde der Ukraine: Geografitscheskaja struktura wneschnej torgowlja Ukrainy towarami (Die geographische Struktur des Außenhandels der Ukraine nach Waren), unter: <http://www.ukrstat.gov.ua/>. Letzter Zugriff am 12. März 2014

Grafik 9: Die führenden 10 Handelspartner der Ukraine 2013: Importe (in \% zu den gesamten Importen)

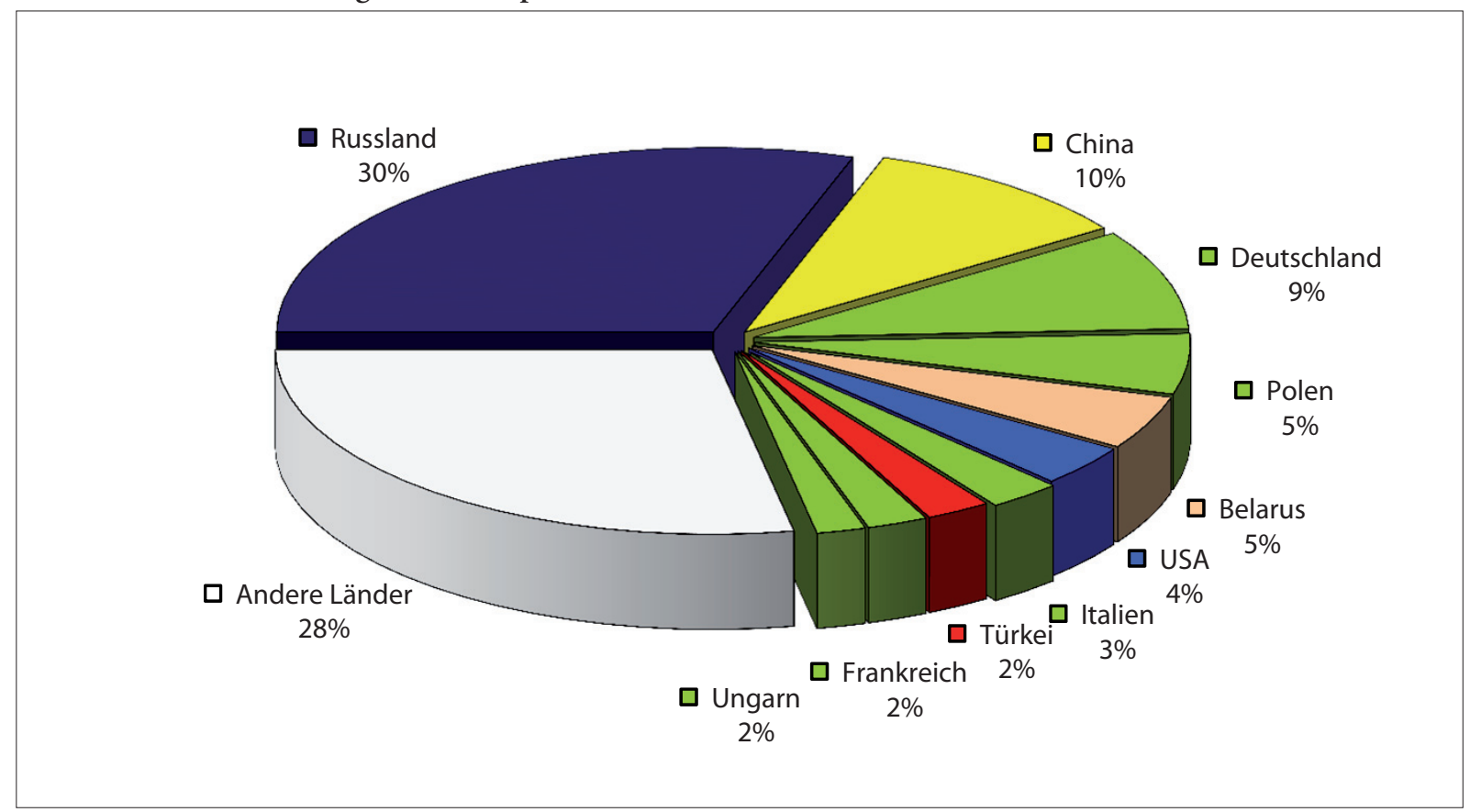

Quelle: Staatliche Statistikbehörde der Ukraine: Geografitscheskaja struktura wneschnej torgowlja Ukrainy towarami (Die geographische Struktur des Außenhandels der Ukraine nach Waren), unter: <http://www.ukrstat.gov.ua/>. Letzter Zugriff am 12. März 2014 


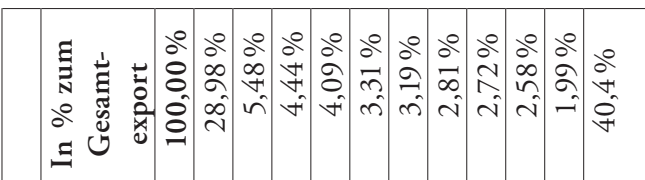

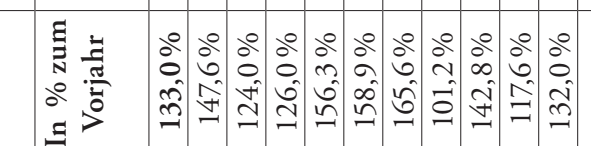

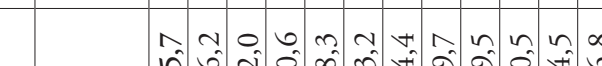

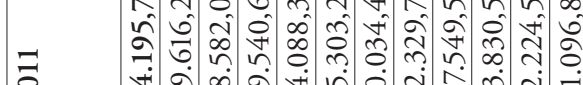

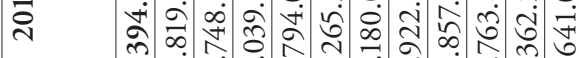

कृ

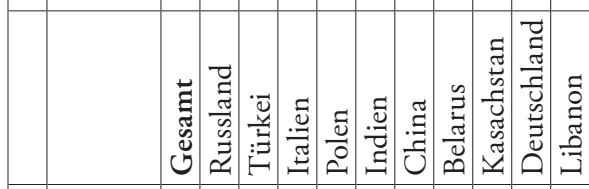

考当

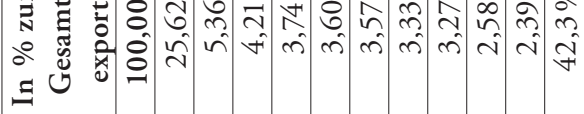

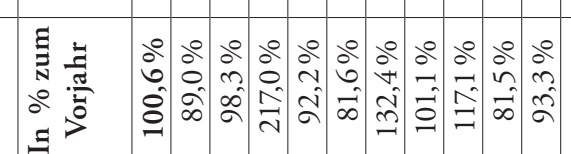

\begin{tabular}{|c|c|c|c|c|c|c|c|c|c|c|c|c|c|c|c|c|c|c|c|c|}
\hline & $\begin{array}{ll}0 \\
5\end{array}$ & 8 & $\stackrel{\bar{N}}{\infty}$ & $\hat{\sigma}$ & to & $\overrightarrow{0}$ & $\triangle$ & $a$ & & & $\Xi>$ & हิ & 完 & 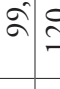 & 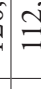 & I & $\exists$ & & $\stackrel{\sim}{\approx}$ & \\
\hline & $\stackrel{\sim}{\stackrel{2}{*}}$ & 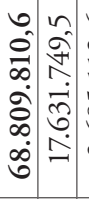 & 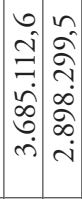 & 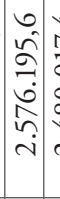 & & 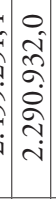 & 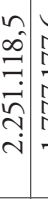 & & 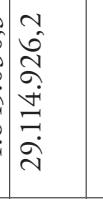 & & ্ָ & 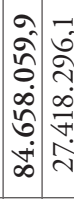 & 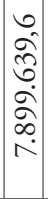 & 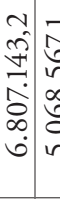 & g & ڤ̊ & & & & 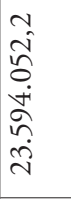 \\
\hline & & 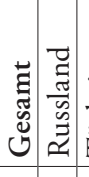 & 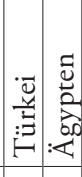 & & & : & & & & & & 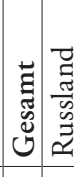 & & 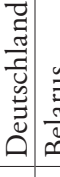 & & & & & & \\
\hline & 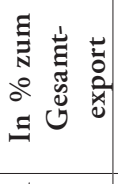 & \begin{tabular}{l|l|}
0 & 0 \\
0 & 0 \\
0 & 0 \\
0 & 0 \\
0 & 0 \\
0 & $n$
\end{tabular} & 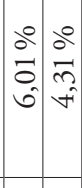 & 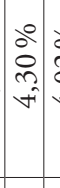 & & $\begin{array}{l}0 \\
0 \\
2 \\
n \\
n \\
m\end{array}$ & & & 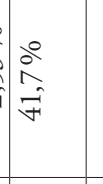 & & 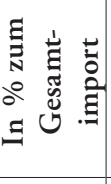 & $\begin{array}{ll}\circ & 0 \\
0 & 0 \\
0 & 0 \\
0 & 0 \\
0 & 0\end{array}$ & $\mid \begin{array}{l}0 \\
\hat{N} \\
0 \\
0 \\
-1\end{array}$ & & & $\mid$ & i & & & $\begin{array}{l}\therefore 0 \\
0 \\
\infty \\
i \\
\sim\end{array}$ \\
\hline & 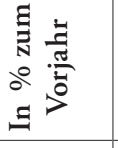 & 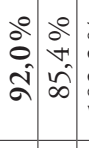 & 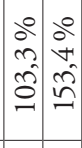 & $\begin{array}{l}\stackrel{0}{2} \\
\text { ळे} \\
2\end{array}$ & $\begin{array}{ll}0 \\
0 \\
0 \\
2\end{array}$ & 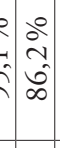 & & & & & 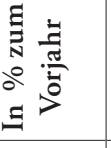 & 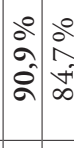 & $\mid \begin{array}{l}0 \\
0 \\
0 \\
0 \\
0\end{array}$ & 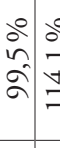 & & $\mid \begin{array}{c}0 \\
0 \\
0 \\
a \\
a\end{array}$ & 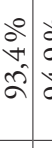 & & $\mid \begin{array}{l}0 \\
0 \\
0 \\
0 \\
0 \\
0\end{array}$ & \\
\hline & ปั่ & 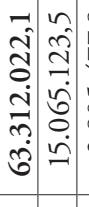 & 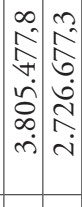 & 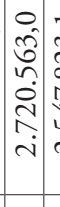 & 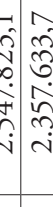 & 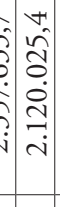 & 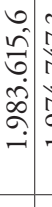 & 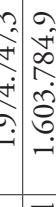 & 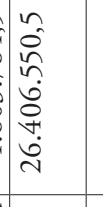 & & సิ & 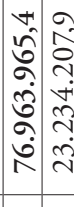 & 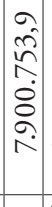 & 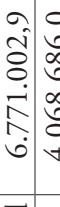 & Fi & $\begin{array}{c}\sim \\
\tilde{\alpha} \\
\tilde{\sigma} \\
\tilde{n} \\
\hat{i}\end{array}$ & 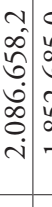 & 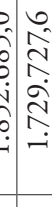 & 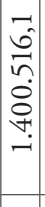 & 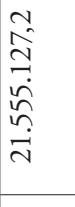 \\
\hline 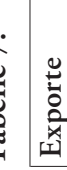 & & 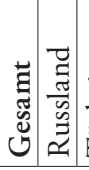 & 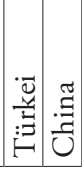 & 竎 & & 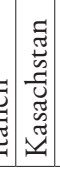 & & & 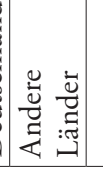 & 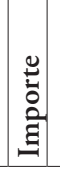 & & 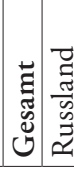 & & 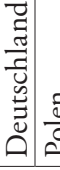 & & & & & & 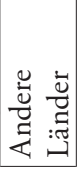 \\
\hline
\end{tabular}

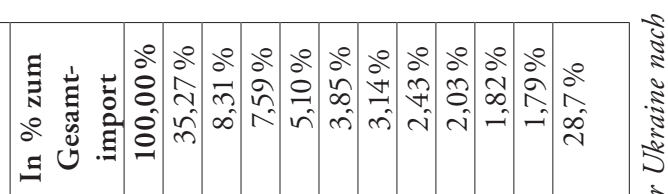

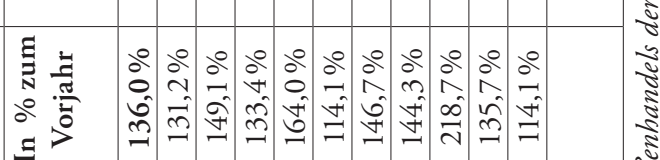

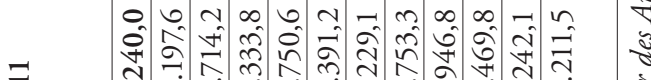

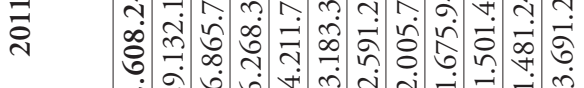
id

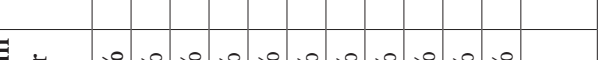

$\frac{\sqrt{2}}{\sqrt{2}}$ 


\section{Russland und die Ukraine in aktuellen Meinungsumfragen}

Der Maidan in russischer und ukrainischer Sicht

Grafik 10: Was treibt die Menschen bei den Protestaktionen im Kiewer Stadtzentrum an? (in \% aller Befragten, beliebige Zahl an Antworten)

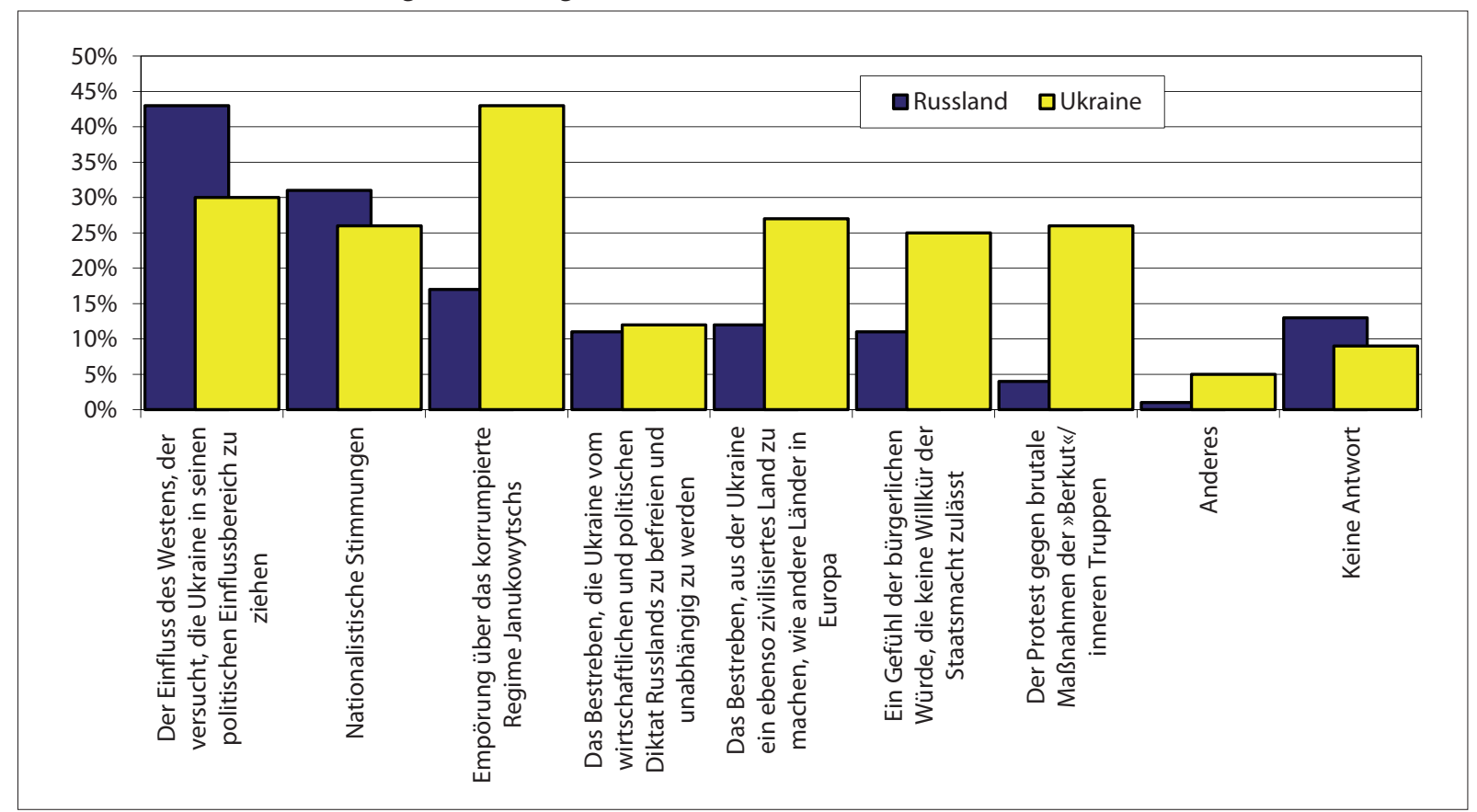

Gemeinsame soziologische Umfrage des Lewada-Zentrums und des "Kiewer Internationalen Instituts für Soziologie«; Umfragen des Lewada-Zentrums vom 21.-25. Februar 2014, N =1603, Repräsentativumfrage in Russland; Umfragen des Kiewer Internationalen Instituts für Soziologie vom 8.-18. Februar 2014, N =2023, Repräsentativumfrage in der Ukraine, veröffentlicht am 3. März 2014 unter: <http://www.levada.ru/03-03-2014/otnoshenie-zhitelei-ukrainy-i-rossii-k-sobytiyam-v-ukraine>

Grafik 11: Was treibt die Menschen zu den Protestaktionen im Kiewer Stadtzentrum? (Ukrainische Regionen, in \% aller Befragten, beliebige Zahl an Antworten)

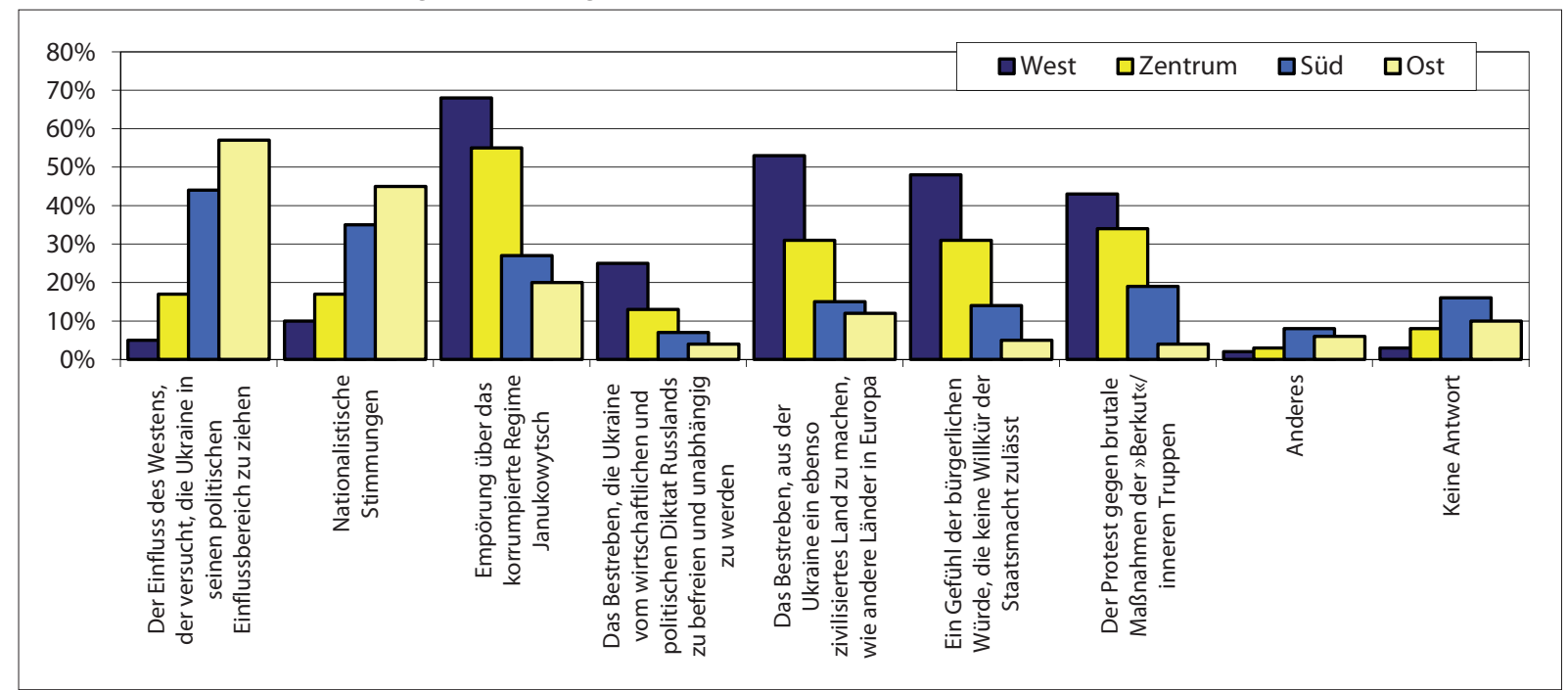

Gemeinsame soziologische Umfrage des Lewada-Zentrums und des "Kiewer Internationalen Instituts für Soziologie"; Umfragen des Lewada-Zentrums vom 21.-25. Februar 2014, $N=1603$, Repräsentativumfrage in Russland; Umfragen des Kiewer Internationalen Instituts für Soziologie vom 8.-18. Februar 2014, $N=2023$, Repräsentativumfrage in der Ukraine, veröffentlicht am 3. März 2014 unter: <http://www.levada.ru/03-03-2014/otnoshenie-zhitelei-ukrainy-i-rossii-k-sobytiyam-v-ukraine> 
Grafik 12: Wer trägt am ehesten die Verantwortung für die Eskalation des Konflikts in der Ukraine? (in \% aller Befragten, beliebige Zahl an Antworten)

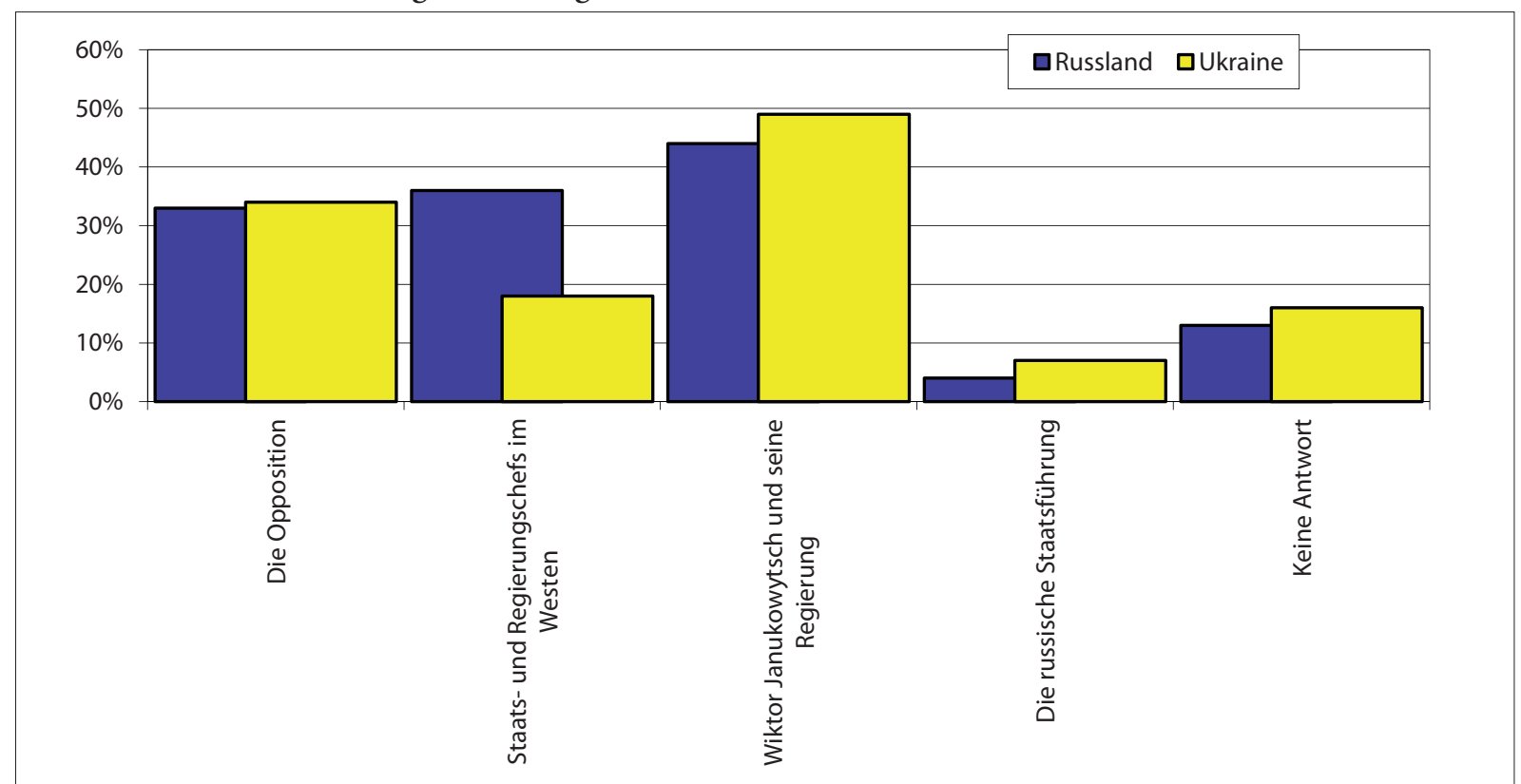

Gemeinsame soziologische Umfrage des Lewada-Zentrums und des "Kiewer Internationalen Instituts für Soziologie "; Umfragen des Lewada-Zentrums vom 21.-25. Februar 2014, $N=1603$, Repräsentativumfrage in Russland; Umfragen des Kiewer Internationalen Instituts für Soziologie vom 8.-18. Februar 2014, N=2023, Repräsentativumfrage in der Ukraine, veröffentlicht am 3. März 2014 unter: <http://www.levada.ru/03-03-2014/otnoshenie-zhitelei-ukrainy-i-rossii-k-sobytiyam-v-ukraine>

Grafik 13: Wer trägt am ehesten die Verantwortung für die Eskalation des Konflikts in der Ukraine? (Ukrainische Regionen, in \% aller Befragten, beliebige Zahl an Antworten)

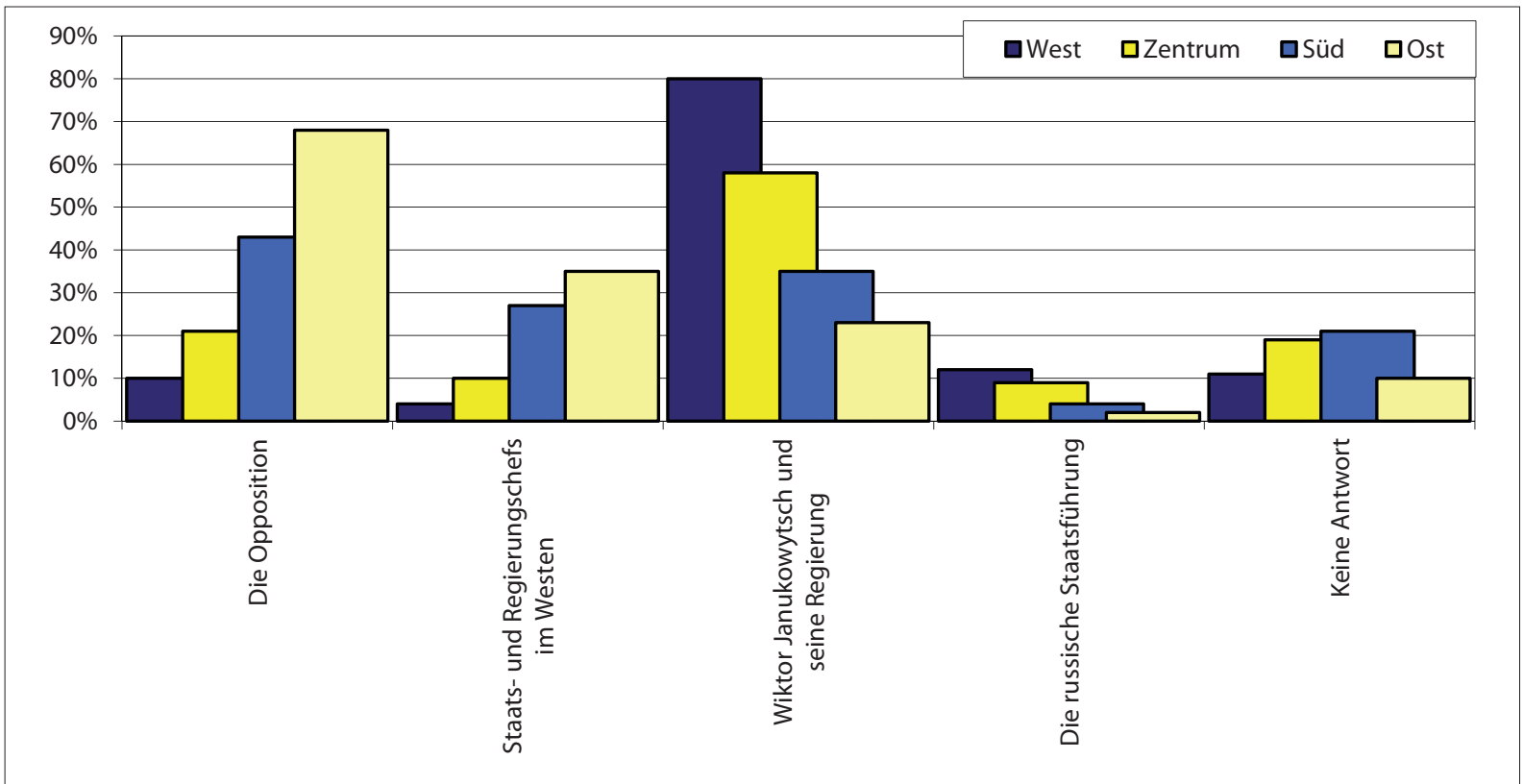

Gemeinsame soziologische Umfrage des Lewada-Zentrums und des "Kiewer Internationalen Instituts für Soziologie«; Umfragen des Lewada-Zentrums vom 21.-25. Februar 2014, $N=1603$, Repräsentativumfrage in Russland; Umfragen des Kiewer Internationalen Instituts für Soziologie vom 8.-18. Februar 2014, N = 2023, Repräsentativumfrage in der Ukraine, veröffentlicht am 3. März 2014 unter: <http://www.levada.ru/03-03-2014/otnoshenie-zhitelei-ukrainy-i-rossii-k-sobytiyam-v-ukraine> 
Grafik 14: Auf wessen Seite sind Ihre Sympathien im gegenwärtigen Konflikt in der Ukraine?

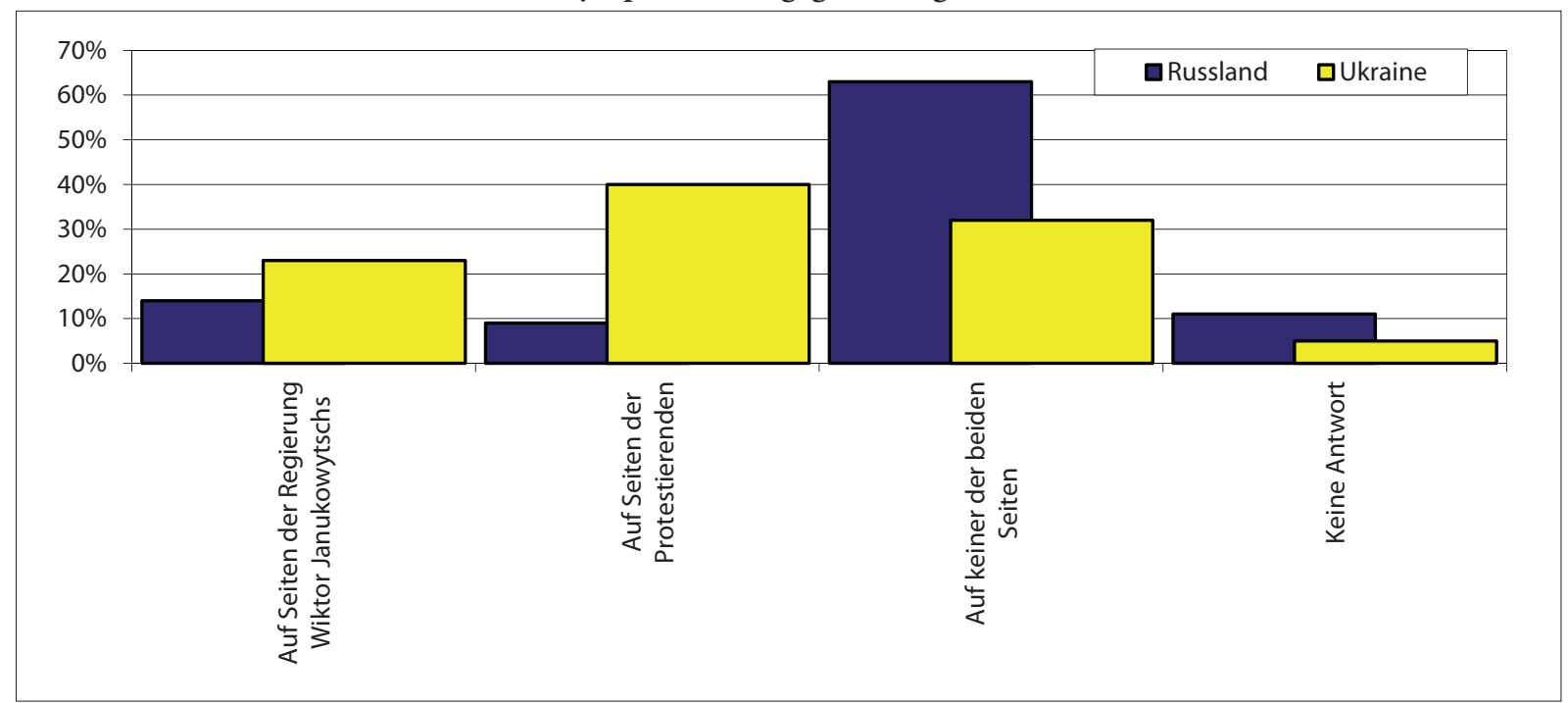

Gemeinsame soziologische Umfrage des Lewada-Zentrums und des "Kiewer Internationalen Instituts für Soziologie«; Umfragen des Lewada-Zentrums vom 21.-25. Februar 2014, N =1603, Repräsentativumfrage in Russland; Umfragen des Kiewer Internationalen Instituts für Soziologie vom 8.-18. Februar 2014, $N=2023$, Repräsentativumfrage in der Ukraine, veröffentlicht am 3. März 2014 unter: <http://www.levada.ru/03-03-2014/otnoshenie-zhitelei-ukrainy-i-rossii-k-sobytiyam-v-ukraine>

Grafik 15: Auf wessen Seite sind Ihre Sympathien im gegenwärtigen Konflikt in der Ukraine? (Ukrainische Regionen, in \% aller Befragten, beliebige Zahl an Antworten)

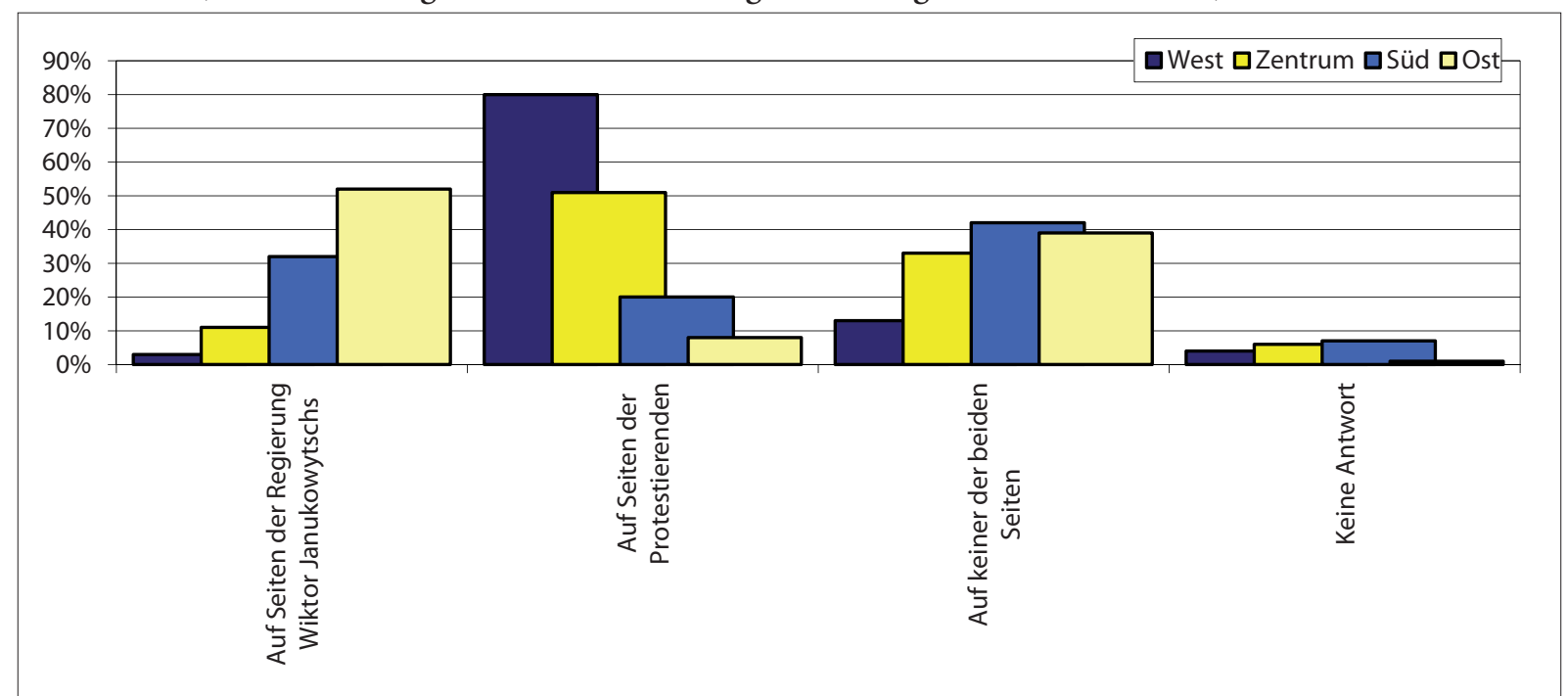

Gemeinsame soziologische Umfrage des Lewada-Zentrums und des "Kiewer Internationalen Instituts für Soziologie«; Umfragen des Lewada-Zentrums vom 21.-25. Februar 2014, $N=1603$, Repräsentativumfrage in Russland; Umfragen des Kiewer Internationalen Instituts für Soziologie vom 8.-18. Februar 2014, N = 2023, Repräsentativumfrage in der Ukraine, veröffentlicht am 3. März 2014 unter: <http://www.levada.ru/03-03-2014/otnoshenie-zhitelei-ukrainy-i-rossii-k-sobytiyam-v-ukraine> 


\section{Der Maidan in russischen Umfragen}

Grafik 16: Was geschieht Ihrer Ansicht nach gegenwärtig in Kiew?

(in \% derer, die von den jüngsten Ereignissen in Kiew gehört haben)

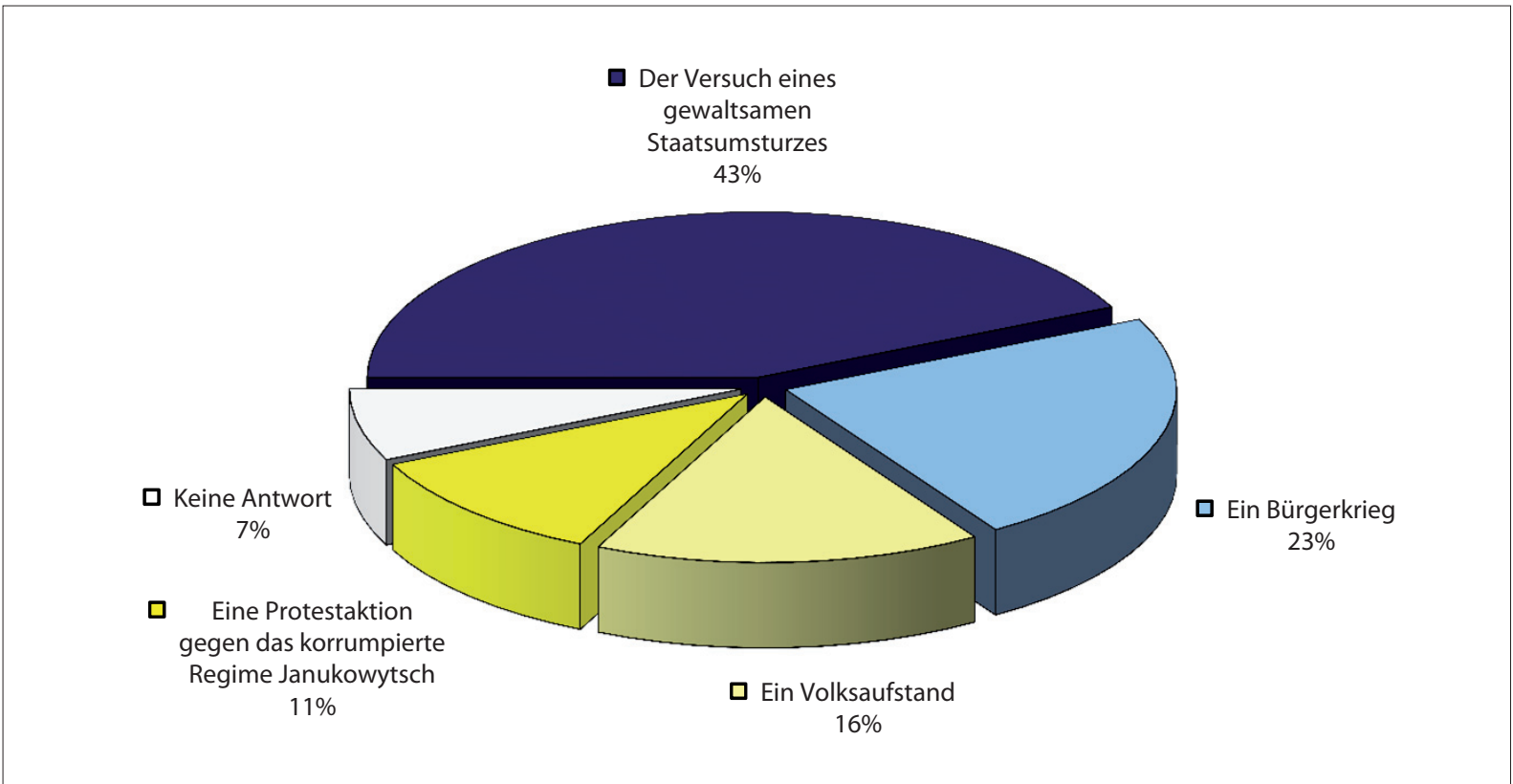

Quelle: Umfragen des Lewada-Zentrums vom 21.-25. Februar 2014, $N=1603$. Veröffentlicht am 26. Februar 2014 unter: <http://www.levada.ru/print/26-02-2014/rossiyane-o-sobytiyakh-v-ukraine-maidan>

Grafik 17: Was treibt die Menschen zu den Protestaktionen im Kiewer Stadtzentrum? (in \% derer, die von den Protestaktionen in Kiew gehört haben, beliebige Zahl an Antworten)

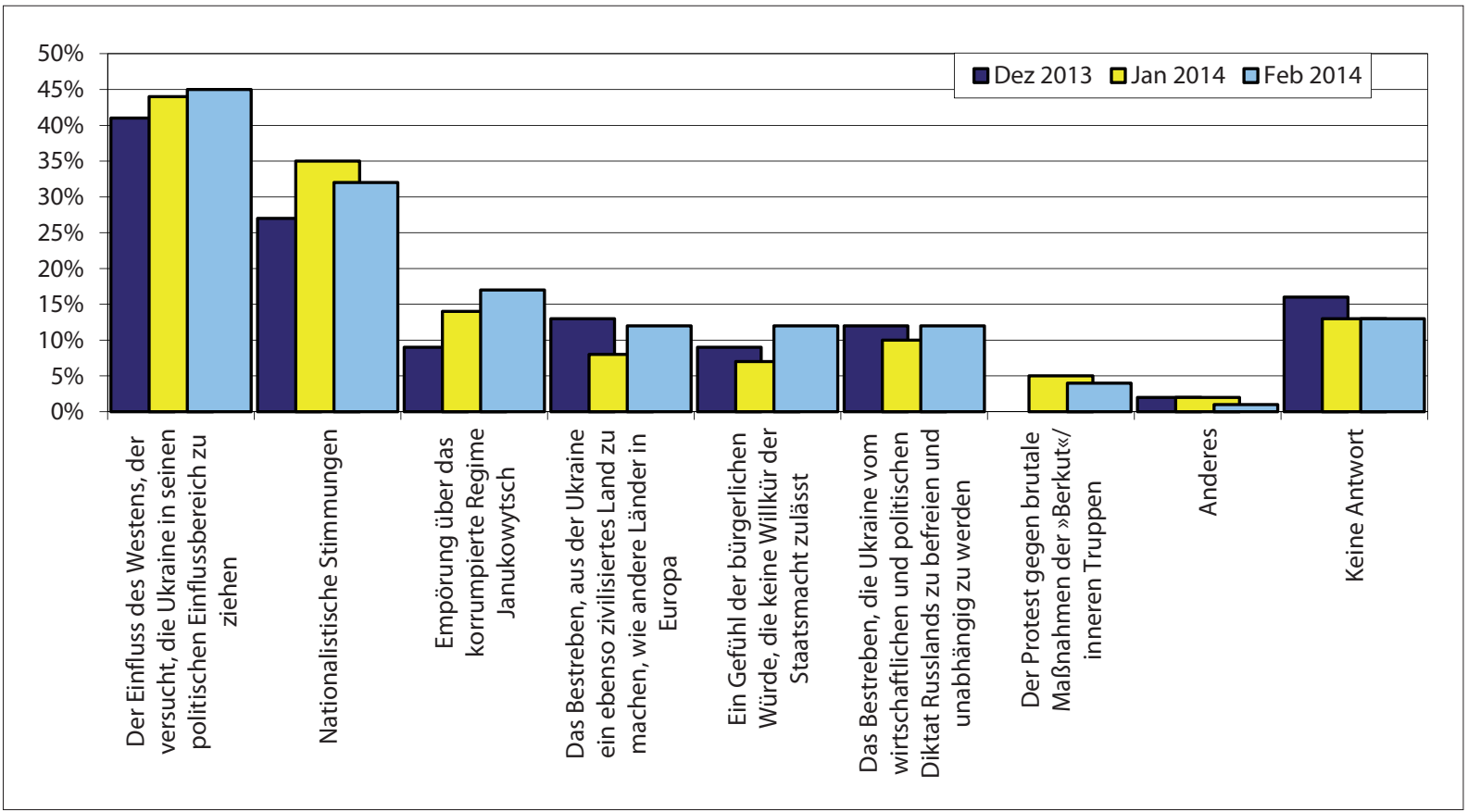

Quelle: Umfragen des Lewada-Zentrums vom 21.-25. Februar 2014, $N=1603$. Veröffentlicht am 26. Februar 2014 unter: <http://www.levada.ru/print/26-02-2014/rossiyane-o-sobytiyakh-v-ukraine-maidan> 


\section{Die Krim-Frage}

Grafik 18: Sollte Russland die Interessen der Russen auf der Krim aktiver verteidigen - oder sollten die Beziehungen zur Ukraine nicht belastet werden?

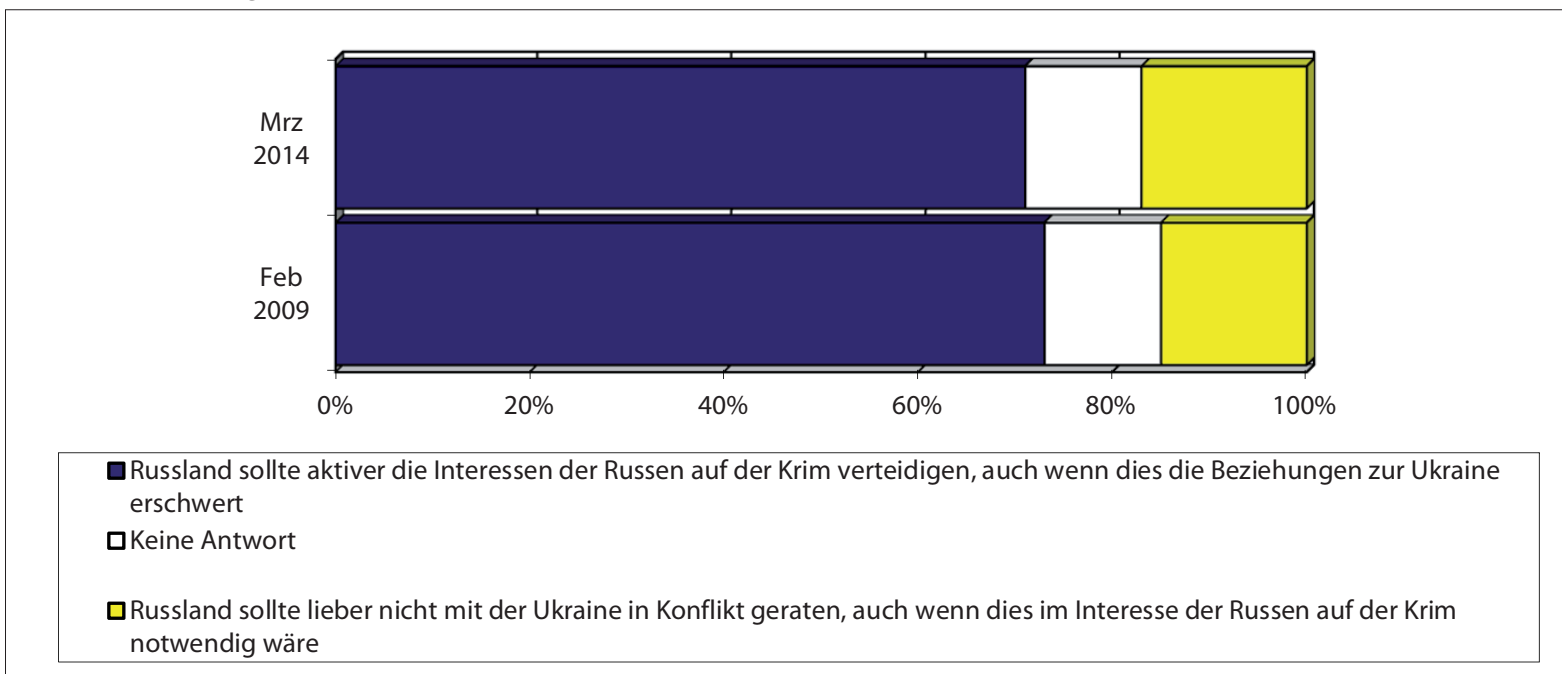

Quelle: Umfragen des WZIOM vom 1.-2. März 2014, N = 1600. Veröffentlicht am 11. März 2014 unter: <http://wciom.ru/index.php?id=515\&uid=114736>

\section{Putins Rating}

Grafik 19: Haben Sie einen positiven oder einen negativen Eindruck von Wladimir Putin?

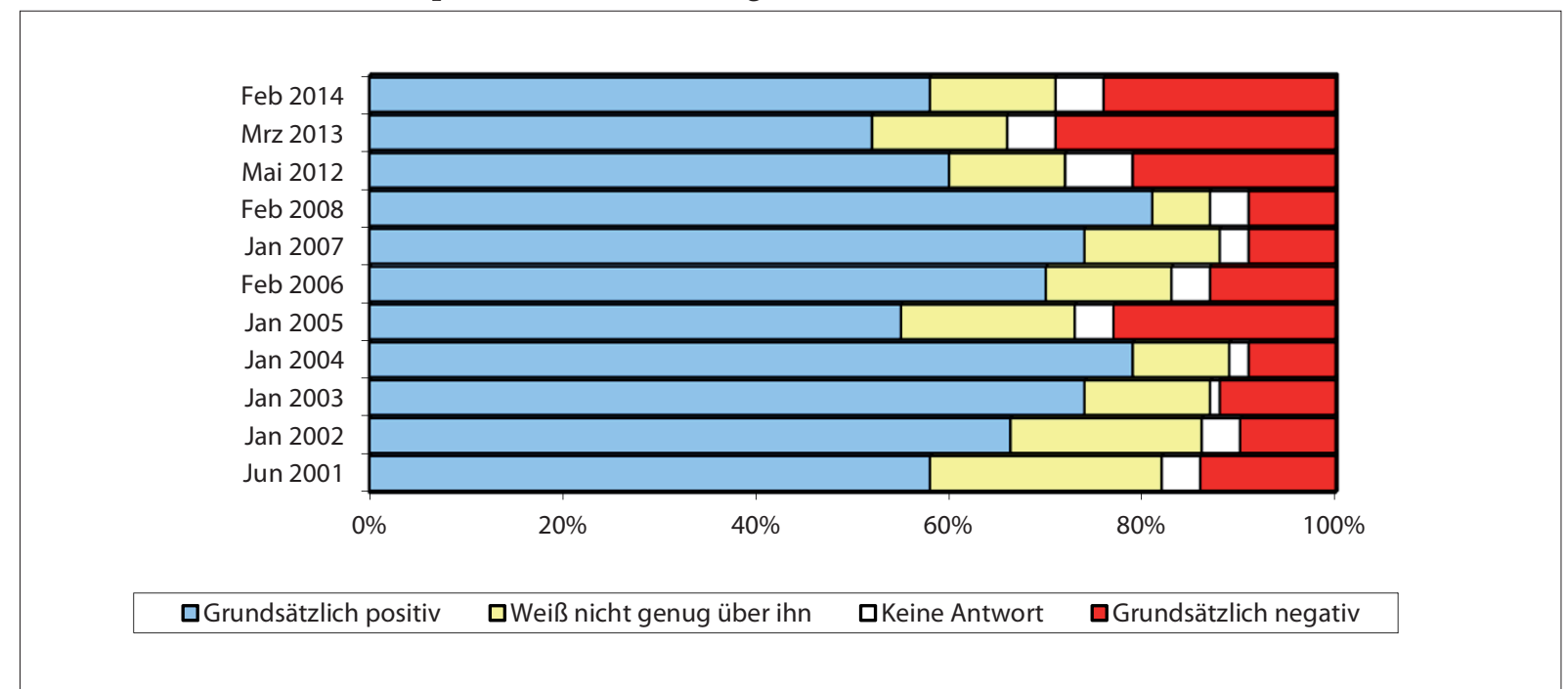

Quelle: Umfragen des Lewada-Zentrums vom 21.-25. Februar 2014, $N=1603$. Veröffentlicht am 5. März 2014 unter: <http://www.levada.ru/05-03-2014/rossiyane-o-vladimire-putine> 
Grafik 20: In welchem Maße beeinflusst Wladimir Putin, was in Russland geschieht?

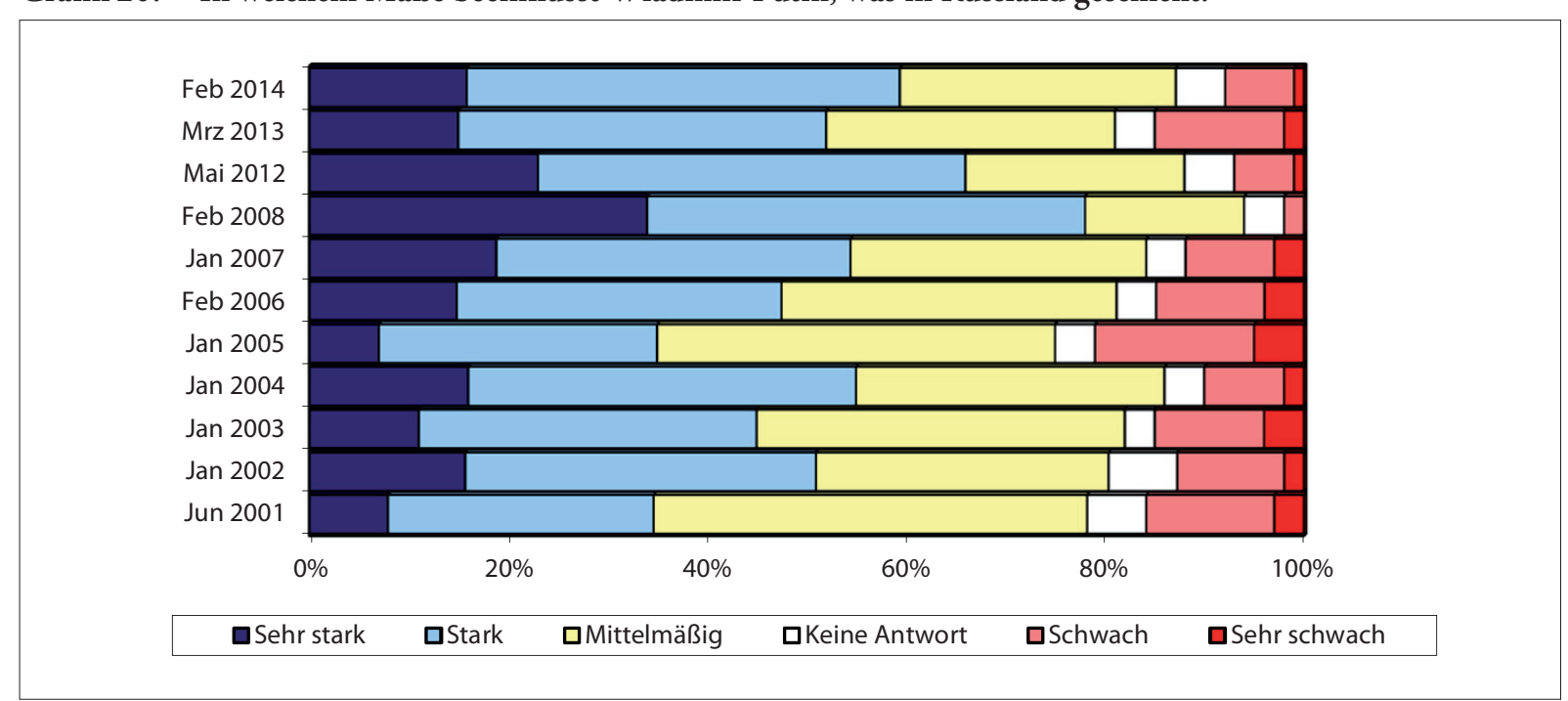

Quelle: Umfragen des Lewada-Zentrums vom 21.-25. Februar 2014, $N=1603$. Veröffentlicht am 5. März 2014 unter: $<$ http://www.levada.ru/05-03-2014/rossiyane-o-vladimire-putine>

\section{Aus der russischen Presse}

\section{Sechs Szenarien}

Pawel Bykow, Olga Wlassowa, Geworg Mirsajan

Die vergangenen Konsultationen haben gezeigt, dass es für Moskau niemanden gibt, mit dem es über die Zukunft der Ukraine reden könnte. Die Europäische Union ist nicht nur zu keinerlei drastischen Entschlüssen bereit, sondern auch nicht in der Lage, den selbst eingegangenen Verpflichtungen gemäß zu handeln. Hinzu kommt, dass im Mai in der EU die Wahlen zum Europaparlament anstehen und die Europäische Kommission neu besetzt wird. Die derzeitige ukrainische Regierung wird von Russland nicht anerkannt, und die Aussichten dieser Regierung sind höchst unklar, da der geschäftsführende Präsident Alexander Turtschynow und der geschäftsführende Ministerpräsident Arsenij Jazenjuk weder über die Ressourcen noch über die Autorität oder den Willen verfügen, um das Land in einer kritischen Situation zu lenken. Für das Szenario einer Angliederung der Krim spricht auch die Erklärung des russischen Präsidenten Wladimir Putin, der in einem Telefongespräch mit US-Präsident Barack Obama festgestellt hat, dass Russland die an Moskau ergangenen Hilferufe von Bewohnern der Krim und anderer Regionen der Ukraine nicht ignorieren könne, wenn die derzeitige ukrainische Führung, die durch einen verfassungswidrigen Umsturz an die Macht gelangte und über kein gesamtnationales Mandat verfügt, absolut illegitime Beschlüsse oktroyiert.

Die Situation in der Ukraine ist derart, dass Russland nicht nur aus humanitären, sondern auch aus rein pragmatischen Gründen die Haltung der Bewohner der Krim und anderer ukrainischer Regionen tatsächlich nicht ignorieren kann. [...] Quelle: Expert; 11 (890), 8. März 2014; <http://expert.ru/expert/2014/11/shest-stsenariev/>

\section{Strategie einer unbequemen Partnerschaft}

Dmitrij Jewstafjew, Dr. der politischen Wissenschaften

Für Russland steht ein Paradigmenwechsel sowohl der innen- wie der außenpolitischen Entwicklung an. Die Weltlage hat eine Dynamik angenommen, bei der die Taktik der »vernünftigen Passivität«, die Russland Erfolge eingebracht hat (man denke nur an das Hin und Her der ägyptischen Revolution, das durch die Wiederherstellung des Systems 
der militärischen und technischen Zusammenarbeit zwischen Kairo und Moskau ein Ende fand), seine Wirksamkeit verlieren könnte. Diese Taktik bringt nur dann Ergebnisse, wenn sie auf einer Reihe geopolitischer und geoökonomischer Konstanten basiert.

Die Konstanten stellen sich für Russland folgendermaßen dar: Zum einen ist da der Vorrang der Zollunion vor anderen Institutionen des postsowjetischen Raumes; und die faktische Anerkennung des Zerfalls des postsowjetischen Raumes. Als zweites ist die deklarierte strategische Partnerschaft mit der Volksrepublik China bei gleichzeitiger Stagnation der realen Zusammenarbeit und einer fehlenden strategischen Agenda zu nennen (dieser Eindruck hat sich besonders nach der durch Peking praktisch vollzogenen »Privatisierung« der Schanghai-Organisation für Zusammenarbeit verstärkt). Drittens das deklarierte Streben nach einer Partnerschaft mit der EU, während im Bereich der realen Politik die konfrontativen Elemente zunehmen. Und viertens die zunehmende verbale Konfrontation mit den USA bei einer äußerst langen Liste von Fragen.

Quelle: Expert, 11 (890), 7. März 2014; <http://expert.ru/expert/2014/11/strategiya-neudobnogo-partnerstva/>

\section{Aus der Redaktion: Biegung in der Pipeline}

Die möglichen Sanktionen gegen Russland im Öl- und Gasbereich können nicht schnell wirksam werden und werden jetzt, in der heißen Phase der Ukraine-Krise, kaum einen politischen Effekt haben. Aber die Zuspitzung der Beziehungen zwischen Russland und der Ukraine könnte die sich in Europa und den USA seit Langem abzeichnende Umstrukturierung des Marktes für Energieträger beschleunigen.

Europa hängt zu rund $30 \%$ von Gas aus Russland ab und zu $27 \%$ vom dortigen Öl. Die Importe aus Russland sind auf die Schnelle nicht zu ersetzen, wobei sich die Abhängigkeit vom Gas wegen der langfristigen Verträge über Lieferungen durch die Pipelines von »Gazprom« dramatischer darstellt. Dass Moskau auf die "Energiewaffe« in Form von überzähligen und teuren Gaspipelines nach Europa gesetzt hat, arbeitet jetzt präzise. Zu Friedenszeiten hat man "Gazprom« noch wegen Ineffizienz, Schwerfälligkeit, Korruption beim Pipelinebau und anderem kritisieren können zu Kriegszeiten stellt sich heraus, dass der Gasexport nach Europa die Wahrscheinlichkeit europäischer Sanktionen auf ein Minimum reduziert. [...]

Quelle.: Wedomosti; Nr. 40 (3544), 7. März 2014; <http://www.vedomosti.ru/opinion/news/23702351/povorot-truby>

\section{Staat und Gesellschaft: Uns erwartet eine Mobilisierungspolitik Jewgenij Gontmacher}

Wie auch immer die russisch-ukrainische Krise ausgehen wird, es lässt sich bereits jetzt konstatieren: Es wird forciert zu einer Gesellschaftspolitik des mobilisierenden Typus übergegangen.

Warum habe ich das Wort "forciert" verwendet? Bereits im vergangenen Jahr ist allen klar geworden: Die Wirtschaft Russlands ist ernstlich und auf lange Zeit ins Stocken geraten. Das bedeutet, dass die in die Staatskasse fließenden Steuermittel offensichtlich nicht einmal zur Umsetzung jener höchst bescheidenen Verpflichtungen reichen werden, die öffentlich übernommen wurden. Beispielsweise die verkündeten, sehr baldigen Gehaltserhöhungen der öffentlichen Angestellten zumindest auf das Durchschnittsniveau in der jeweiligen Region. Oder eine Anhebung der Renten, die zumindest die Inflation ausgleicht. Vollendete Tatsache, festgeschrieben im Föderalen Haushalt für 2014-2016, ist eine Verringerung (unter anderem eine absolute) der staatlichen Finanzierung des Gesundheits- und Bildungssystems. Quelle: Wedomosti, Nr. 40 (3544), 7. März 2014; <http://www.vedomosti.ru/opinion/news/23675711/evgenij -gontmaher-mobilizacionnye-cherty-novoj-politiki>

\section{Die Europarlamentarier überlegen sich Druckmittel gegen Russland}

\section{Taras Podres, Darja Zoj}

[...]

Die Leiterin des Zentrums für politische Integration des Europa-Instituts der Russischen Akademie der Wissenschaften Ljudmila Babynina ist der Ansicht, dass ein Einfrieren der Guthaben einzelner Personen das wahrscheinlichste Szenario für Sanktionen gegen Russland sei. Ein solcher Schritt würde es der Europäischen Union ermöglichen, den eigenen Wählern und den USA gegenüber das Gesicht zu wahren, und er würde gleichzeitig die Wirtschaftsbeziehungen zu Russland nicht im geringsten beeinträchtigen. Auf eine reale wirtschaftliche Isolierung wird die EU nicht zurückgreifen. Der Warenaustausch mit der EU macht 49\% des russischen Außenhandels aus, laut den Daten für 2013 ist der Warenverkehr mit der EU um 2\% auf 417,5 Mrd. US-Dollar angestiegen (nach Angaben des Föderalen Steuerdienstes). [...]

Quelle: Iswestija; Nr. 40, 5. März 2014 


\section{Das Kindergegschwätz der westlichen Politik}

Sergej Roganow, Philosoph

Die Welt ist schockiert. Nach nur einer Stunde waren Streitkräfte der Russischen Föderation in der Ukraine Realität, und keine Phantasien oder Träumereien. Als sich die Krim und die ukrainische Flotte unter der Flagge Russlands erhoben. Als über den gesamten Südosten der Ukraine eine Welle prorussischer Versammlungen hinwegzog und über den Verwaltungen der Städte und Gebiete Trikoloren Russlands gehisst wurden. Als die Plätze der größten Industriezentren skandierten: »Putin! Russland!« Das Leben Russlands, Europas, der USA verlagerte sich in die Nachrichtenticker, weil man erstmals seit dem Vierteljahrhundert postsowjetischer Wirren tatsächlich nur auf Nachrichten wartete, sie jagte, fieberhaft las; Nachrichten zum Thema »Moskau. Kreml«. [...]

Und wir haben das elementare Gefühl nationaler Selbstachtung noch nicht soweit verloren, dass wir dem Westen erlaubten, unser Land ungestraft zu schikanieren und mit Dreck zu überschütten. Es ohne zu murren, ohne Widerwehr den amerikanischen Expertenhorden erlaubten, sich in der Regierung, den Organen staatlicher Macht auszutoben. Dass wir unsere debil daherkommenden Klugscheißer mit ihren endlosen Absonderungen über "Bolschewiken«, "Diktatur« usw. in die Medien ließen.

Dass wir Idioten erlaubten, ihre Heimat zu unterminieren und ungestraft in die Kommentare Verwünschungen gegen Russland zu streuen und dessen letztendlichen Tod zu beschwören, wegen dessen »endlich endgültigen Zusammenbruchs« zu frohlocken. Gehen Sie nur in die sozialen Netze und lesen sie dort! Da wird von Nordkorea geredet, und von Afghanistan. Von Tyrannen und Interventen. Aber, verehrte Russophobe und Sowjetophobe, alle Duldsamkeit und alle dreisten Taten haben einmal ihr Ende. Behaupten Sie später also nicht, man habe Sie nicht gewarnt.

Aber das für später, sollen sie doch geifern wie tollwütige Hunde.

Jetzt Nachrichten zu kommentieren, ist eine undankbare und riskante Sache, weil im Krieg (und der ist entfacht, ein umfassender und - bislang nur! - Medien- und Propagandakrieg) jeder Kommentar zu spät kommt, ein zukünftiger Kommentar gehört umgehend der Vergangenheit an. Politiker und Analytiker, hier wie im Ausland, wetteifern mit ihren Kindereien.

Quelle: Iswestija; Nr. 38, 02.03.2014; <http://izvestia.ru/news/566844>

\section{Putin verdient den Nachimow-Orden}

Der Schriftsteller Alexander Prochanow über Sieg und Wunder, die wir erwarten

Die Krim ist in aller Munde.

Bangigkeit, Andacht, glänzende Augen. Abergläubische Vorahnungen: Ist es wirklich möglich, wird es wirklich geschehen? Wird die [ethnisch] russische Krim tatsächlich wieder mit Russland vereint sein? Davon spricht man in Sibirien und im Fernen Osten [Russlands], davon spricht man in den Riesenstädten und winzigen Dörflein.

Alle Gedanken, alle Gebete gelten der Krim, sind Vorzeichen einer geheimnisvollen russischen Wiedergeburt, eines russischen geistigen Frühlings. Wir zählen die Tage und Stunden bis zum Referendum. Dass es bloß nicht scheitere. Dass bloß nicht wütende Banden die Krim überfallen. Dass nicht die Mehrfachraketenwerfer an den Straßensperren losgehen. Dass der Wille der Krimbewohner bloß nicht erschüttert werde oder, verhüt's Gott, die [national]russische Politik sich verschiebe. In diesen Ängsten liegt auch etwas Religiöses, Erhabenes und Gebethaftes.

Quelle: Iswestija; 10. März 2014 <http://izvestia.ru/news/567223>

\section{Vernichtende Niederlage des Westens. Der Ukraine und des Westens in der Ukraine Andranik Migranjan, Politologe}

[...] Merkwürdig, dass in den westlichen Medien, besonders den amerikanischen, gesagt wird, dass das Volk sich gegen die Regierung in Kiew erhoben habe. Daraus folgt: Wenn sie die Verfassung verletzt und einen Umsturz verübt haben, ist das normal; wenn aber das Volk auf der Krim ebenfalls beschlossen hat, angesichts der illegitimen Regierung in Kiew die ganze Macht in die eigene Hände zu nehmen und sich die örtlichen Behörden, die örtlichen Justiz- und Machtstrukturen zu unterstellen, gilt das nicht als normal, sondern als Verletzung irgendwelcher Gesetze.

Das Vorgehen Russlands (sogar die Maßnahmen jener Einheiten, die einige Garnisonen ukrainischer Truppen blockierten) erfolgte sowohl in Übereinstimmung mit Vereinbarungen mit den Behörden der Krim als auch in Abstimmung mit dem derzeit noch amtierenden Präsidenten der Ukraine. Es ist daher lachhaft, von der Verletzung irgendwelcher Verträge zu sprechen, wenn hiergegen in Kiew Leute protestieren, die - aus der Sicht Russlands - einen bewaffneten Umsturz verübt haben und keine legitime Regierung darstellen.

Quelle: Iswestija; 6. März 2014 <http://izvestia.ru/news/567089> 


\section{Krim: Kriegsszenarien und Sanktionen gegen Russland}

\section{Kriegsszenario auf der Krim}

Die Lage auf der Krim ist angespannt. Die russischen Truppen, die laut Wladimir Putin »Selbstverteidigungskräfte in russischer Uniform« seien, kontrollieren die wichtigsten Infrastrukturobjekte, das Gebäude des Parlaments der Krim sowie regionale Telekommunikationseinrichtungen. Ein besonderes Problem stellen die Militäreinheiten der ukrainischen Armee dar, die zwar noch immer auf der Halbinsel stationiert sind, gleichwohl von den russischen Spezialeinheiten in ihren Kasernen eingesperrt werden. Das russische Militär hat mehrmals versucht, ukrainische Stützpunkte auf der Krim zu stürmen, die eine Kapitulation und eine Überlassung der Munitionslager verweigerten. Die Attacken wurden bisher ohne Waffeneinsatz abgeblockt. Das Referendum am 16. März und eine Annexion der Halbinsel an Russland können dazu führen, dass das ukrainische Militär als ausländische Truppen auf dem Territorium eines fremden Staates gilt. Eine solche Situation könnte von Russland als Gefahr für die staatliche Sicherheit interpretiert werden und letztendlich einen bewaffneten Konflikt in der Region auslösen.

"Ich hoffe mich zu irren, aber die Logik der Entwicklung auf der Krim legt ein Blutvergießen nahe von Sergej Kondraschow, 9. März 2014 <http://www.snob.ru/profile/10815/blog/73285>

"Ich bin 80 Jahre alt, aber ich nehme ein Gewehr und werde mein Land verteidigen"

Leonid Krawtschuk, der erste Präsident der unabhängigen Ukraine, empört sich über die Besatzung der Krim durch russische Truppen. Er kritisiert den Kreml scharf wegen des Verstoßes gegen das Völkerrecht und warnt Russland vor gefährlichen Konsequenzen im Falle des Krieges mit der Ukraine: »Ich rufe die russische Regierung zum Einhalten auf. Zwischen unseren Völkern darf es keinen Krieg geben [...] Alle Länder Europas werden die Ukraine unterstützen. Ich habe keine Zweifel daran. Wir sind Objekt einer Aggression. In dieser Situation müssen wir nur noch klug sein und dürfen keine abrupten Vorstöße zulassen. Nach dem Zweiten Weltkrieg gab es die Nürnberger Prozesse. Ja, das war in Deutschland, kann sich aber auch an einem anderen Ort wiederholen."

"Ich bin 80 Jahre alt, aber ich nehme ein Gewehr und werde mein Land verteidigen" von Leonid Krawtschuk, 2. März 2014 <http://www.snob.ru/profile/28139/blog/72834>

\section{"Es wird keine Sanktionen gegen die Putinsche Administration geben«}

Der Journalist des Radiosenders »Echo Moskwy« Matwej Ganapolski zweifelt an einer Einführung sowie einer Wirkung der Sanktionen gegen Moskau. Die wirtschaftlichen Beziehungen zwischen den Ländern der Europäischen Union und Russland sind eng und für beide Konfliktseiten sehr wichtig. Europa müsste dafür zu hohen Preis zahlen: »So brummelt Frankreich etwas von Visafragen und Sanktionen und traut sich in Wirklichkeit nicht mal, den Namen Wladimir Putin zu erwähnen, weil die Franzosen für uns den Flugzeugträger »Mistral« bauen [eigentlich geht es um zwei Hubschrauberträger, S.M.], und dieser Vertrag wird Russland 1 Milliarde Euro kosten. Sollte sich Frankreich jetzt für Sanktionen entscheiden, würde Russland sehr wahrscheinlich auf den Kauf verzichten. Und so funktioniert es überall. Die UNO kann nichts machen, weil sofort ein Veto käme, und die mächtigsten Staaten sind durch ihre Wirtschaftsbeziehungen, durch Gas, Pipelines usw. mit Russland verflochten, was Ehrlichkeit und gesunden Menschenverstand raubt."

"Ihr macht euch vor Angst in die Hosen!" von Matwej Ganapolski, 7. März 2014 <http://www.echo.msk.ru/blog/ ganapolsky/1274402-echo/>

\section{Kann sich Russland einen Sanktions-Krieg leisten?}

Sanktionen als Strafe sind in erster Linie auf eine Schwächung der Volkswirtschaft eines Aggressors gerichtet. Im Fall Russland hätten Brüssel und Washington zumindest aus makroökonomischen Gründen mehr Spielraum als Moskau. Die russische Wirtschaft ist im Vergleich zur amerikanischen oder zur europäischen rund sieben Mal kleiner. Russland könnte sich bei einem Sanktions-Krieg kaum wehren, ohne sich selbst zu schaden. Theoretisch hätte Russland die Gas-Geschäfte, seine Währungsdevisen, ausländisches Eigentum und Tochterunternehmen internationaler Konzerne aufs Spiel setzen können. Eine genaue Betrachtung dieser Instrumente zeigt ebenfalls, dass ihr Einsatz unwahrscheinlich ist, meint der Prorektor des Higher School of Economics Konstantin Sonin. Für einen effektiven Einsatz ausländischer Währungen verfügt Russland über viel zu geringe Devisenbestände in US-Dollars oder Euros. Das Procedere einer Beschlagnahmung ausländischer Unternehmen wäre äußerst schwierig, da von diesen viele de jure als russische Unternehmen registriert sind. Die eigenen Verluste wären dabei deutlich höher. 
Viel wahrscheinlicher scheint der Einsatz von »leichteren Sanktionen«, die sich der Kreml durchaus leisten kann. Dazu gehören beispielsweise Importverbote für bestimmte Lebensmittel. Die Wirkung solcher Instrumente ist allerdings gering.

"Ach, du willst mit dem Helm prügeln..."von Konstantin Sonin, 10. März 2014 <http://www.echo.msk.ru/blog/ ksonin/1275900-echo/>

\section{„Dawai, Barak, Dawai!«}

Der Kommunalpolitiker Oleg Dubow aus Twer kritisiert die US-Politik wegen Doppelstandards in der UkraineFrage: „Als zum Jahreswechsel auf dem Maidan statt Väterchen Frost der \liebe Onkel McCain erschien und Victoria Nuland die `Rebellen` mit Piroggen fütterte, hat kein Mensch von Sanktionen gegen die USA gesprochen."Gleichzeitig verweist Dubow auf mögliche positive Auswirkungen, die Sanktionen für die Wirtschaft Russlands könnten. Das Sperren von ausländischen Konten russischer Beamten würde die Politik Putins zur "Deoffshorisazija« (Entoffshorisierung) befördern. Ein Ausschluss Russlands aus der G8-Gruppe würde lediglich symbolische Bedeutung haben: „Das heutige China bemüht sich nicht um die G8-Mitgliedschaft und fühlt sich wohl dabei«. Ein Ausscheiden Russlands aus dem Sicherheitsrat der Vereinten Nationen wäre undenkbar. Durch die Suspendierung der Mitgliedschaft bei den sonstigen Organisationen und "Partnerschaften« würde der Westen Russland nur einen Gefallen tun, behauptet Dubow und plädiert für einen Austritt Russlands aus dem Europarat, »einer weiteren nutzlosen Organisation, die so gern alles und jeden ein Leben nach liberaler Manier lehren möchte«. Im Falle von Sanktionen müsste Moskau allerdings adäquate Antworten geben: Die Sperrung des Luftraums für NATO-Flugzeuge sowie den Tausch der Dollarreserven in andere Währungen.

"Dawaj, Barak, dawaj!' von Oleg Dubow, 10. März 2014 <http://www.echo.msk.ru/blog/oleg_dubov/1275990-echo/>

\section{Andere Realitäten}

Jens Siegert, Moskau

Langsam, immer noch erstaunlich langsam angesichts der wohl bevorstehenden Annexion der Krim durch Russland, ändert sich die Wahrnehmung im Westen, wie mit Russland und seinem Präsidenten Putin denn nun umzugehen sei. Ich meine damit nicht diejenigen, die es immer schon sicher wussten: die einen, dass der russische Präsident ein »lupenreiner Demokrat" sei, oder andere, dass er ein ewiger KGB-Agent sei, der sich aus dem "Reich des Bösen« herübergerettet hat. Wer in so holzschnittartigen Kategorien urteilt, hält Russland und seine Menschen für einen hoffnungslosen Fall, weder in der Lage zu demokratischer Entwicklung, noch in irgendeiner Weise verstehbar.

Ich meine diejenigen, die sich seit Jahren damit abmühen, die russische Politik zu verstehen, ihr die eine oder auch die andere Ratio zuzuordnen, Angebote zu machen, enttäuscht zu werden oder erfreut, kurz, all diejenigen, die Russland als ein Land wie jedes andere behandeln, das nur vielleicht ein wenig zu groß geraten ist und eine etwas zu bittere Vergangenheit hat.

Eine Aussage, von der niemand weiß, ob sie überhaupt so und von der Person, der sie zugeschrieben wird, gemacht wurde (sie wird uns durch die New York Times nur vom Hörensagen übermittelt), ist das vielleicht deutlichste Anzeichen für diese Wahrnehmungsverschiebung. Angela Merkel soll Anfang voriger Woche, kurz nach dem Krimeinmarsch, in einem Telefonat mit Barack Obama über Putin gesagt haben, sie sei nicht sicher ob er noch "in touch with reality" sei, er lebe womöglich »in another world«.

Allgemein wurde das schnell so interpretiert, dass Merkel Putin für nicht mehr ganz zurechnungsfähig halte. Doch das ist nur eine mögliche Sichtweise, die sich auf die Worte "reality« und »world» konzentriert. Damit wäre einfach nicht mehr verständlich, was Putin denkt und macht und warum er es denkt und macht. 
Man hätte es mit einem im Wortsinn »Verrückten« zu tun. Und das wäre sehr schwer.

Eine andere Sichtweise würde sich auf das »another" konzentrieren. Und dann versuchen, diese »andere « Welt oder Realität zu ergründen. Ansätze dafür gibt es auch in der öffentlichen Debatte. Julia Ioffe zum Beispiel, die hellsichtige Russland-Korrespondentin von The New Republic, gibt eine ganz einfache Antwort: Putin habe seine Truppen in die Ukraine einmarschieren lassen, weil er es kann.

Sie bezieht sich dabei wohl auch auf jene, die Putins Machtelite (und die meisten Menschen in Russland mit ihm) schlicht für Leute des 20. oder gar 19. Jahrhunderts halten. Sie, so geht das Argument, seien mit ihrem geopolitischen Gleichgewichtsdenken sowohl rechtlich als auch moralisch in einer Zeit stehen geblieben, in der Kriege in Europa noch für führbar gehalten wurden. Zu dieser Überlegung gibt es noch eine Kehrseite. Sie schilt Putin nicht für diese (angebliche) Rückständigkeit (oder Rückwärtsgewandtheit), sie bewundert ihn dafür (wenn auch mitunter nur heimlich). Denn Putin habe erkannt, dass der Westen (besonders natürlich Europa und insbesondere Deutschland) sich mit seinem Verlassen auf eine Verrechtlichung internationaler Beziehungen und seiner Vernachlässigung alles Militärischen in ein Wolkenkuckucksheim verrannt habe (hier klatschen alle Geopolitiker von Putin bis Kissinger).

All das stimmt: die Julia-Ioffe-Feststellung, die Rückwärtsgewandtheit, die Feststellung, dass Geographie immer noch, wenn auch angesichts der technischen Entwicklung ein wenig weniger als früher, eine wichtige Rolle spielt. Nur erklärt es auch zusammen genommen nicht oder zumindest mir nicht ausreichend, warum sich Putin offenbar zu dem riskanten Schritt entschlossen hat, die Krim zu annektieren (und nicht »nur" von der Ukraine abzuspalten und zu einem Protektorat á la Abchasien oder Südossetien zu machen), also die seit dem Zweiten Weltkrieg bestehende und auf der Unverletzlichkeit der Grenzen aufgebaute internationale Sicherheitsordnung ins Wanken zu bringen.

Angenommen aber, Putin lebe tatsächlich in einer anderen Realität, die er mit den meisten Menschen in Russland teilt. Mit Realitäten ist es ja so ein Ding. Was für die einen real ist, mag für andere ein Hirngespinst sein. Wenn aber solch ein "Hirngespinst", also eine aus westlicher, "aufgeklärter" Sicht erstaunlich nahe an Wahnvorstellungen herankommenden Welt-Vorstellung, nur von genügend Menschen genügend geglaubt wird, dann werden sie (oft erschreckend) real.

Woraus besteht also »Putins Realität«? Putin ist es erneut (wie vor ihm schon vielen anderen russischen Herrschern) gelungen, den tiefen Alltagsgraben zwischen den Menschen und dem Staat in Russland ideo- logisch zu überbrücken. Dabei hat er sich einer Reihe von Vorstellungen bedient, die weit in die russische Geschichte zurück reichen. Da ist zum einen die Vorstellung einer großen Mehrheit, wohl zwei Drittel bis drei Viertel der Bevölkerung, von Russland als einer bewaffneten Großmacht. Die Bewaffnung ist wichtig, denn die Welt ist gefährlich. Hinzu kommt eine hypertrophierte Überzeugung, dass fast alles, was auf der Welt passiert, etwas mit Russland zu tun habe und im Zweifel bewusst gegen das Land gerichtet sei.

Zu dieser Vorstellung einer bewaffneten Großmacht gehört auch die fast mythische Überhöhung der Armee, die heldenhaft ist und edel, deren Soldaten als mit einer vormodern anmutenden Ehrhaftigkeit ausgestattet vorgestellt werden. Die moralische Rechtfertigung einer solchen Sicht liegt immer noch im heldenhaften Freiheitskampf der Roten Armee gegen die nationalsozialistische Aggression. Daraus wird dann in Russland zweierlei abgeleitet. Zum einen eine eigene "antifaschistische" Mission. Zum anderen die Gewissheit, selbst nicht den menschenverachtenden Schimären rechtsnationalistischer Ideologien erliegen zu können. "Faschisten« sind also immer die anderen, diesmal die Ukrainer.

In der Vorstellung einer Mehrheit der Menschen in Russland steht das Staatsoberhaupt außerhalb der Gesellschaft und über dem Gesetz. Es hat alle Macht (alles Recht) und muss sich deshalb nicht verantworten Es muss sich mit niemandem beraten und darf, ja soll alleine entscheiden. Dieser Vorstellung der (Über-) Macht des Staates stellen diese Menschen ihre eigene Jämmerlichkeit (russisch: nitschtoschestwo) entgegen, die vor dem Weltenschicksal nur durch die Größe des Landes aufgehoben wird. Das enthebt dann die Menschen der Notwendigkeit, sich (auch moralisch) entscheiden zu müssen (da von ihnen ohnehin nichts abhängt). Und damit sind sie auch nicht verantwortlich. Die Lebenserfahrung der Menschen in Russland rät ohnehin dazu, große Widersprüche lieber nicht aufzulösen, sondern mit ihnen zu leben (weil sich oft nur so überleben ließ). Man passt sich halt an.

Dank dieser Lebenserfahrungen, deren Projektion nach außen und dank eines seit Jahren donnernden Propagandagetöses, das Russland als eine von Feinden umzingelte Festung des Guten und Wahren in einer grundbösen Welt darstellt, ist es möglich geworden, dass heute die meisten Menschen in Russland so ziemlich genau vom Gegenteil dessen überzeugt sind, was ich für real halte: Ich denke, dass es in der Ukraine einen Aufstand gegen eine korrupte und inkompetente Regierung gegeben hat. In Russland herrscht die Meinung vor, es habe einen vom Westen gesteuerten, "faschistischen" Staatsstreich gegeben. Ich glaube, dass ethnische Russen in der Ukraine nicht um Leib und Leben fürchten 
müssen, nur weil sie ethnische Russen sind. Eine Mehrheit in Russland ist von dieser Gefahr überzeugt. Ich glaube, dass es sich bei den Ereignissen in der Ukraine um vorrangig innerukrainische Auseinandersetzungen handelt, zwar mit äußeren Akteuren, deren Entwicklung aber vor allem in der Ukraine und von Ukrainern vorangetrieben wird. Viele Russen negieren diesen inneren Zusammenhang und machen "äußere Kräfte« verantwortlich. Ich bin davon überzeugt, dass es so etwas wie Demokratie gibt. Für eine Mehrheit in Russland ist Demokratie nur eine besonders abgefeimte Variante der Herrschaftsausübung und eine Waffe des Westens zur Unterdrückung fremder Völker, zuvörderst Russlands. Kurz: Ich glaube an den Eigensinn von Menschen und Gemeinschaften. In Russland können sich viele diesen Eigensinn nur als anarchischen Ausbruch vorstellen.
Das ist die Realität, in der Putin nicht nur lebt, sondern die er (mit) erzeugt hat (und wenn nicht erzeugt, dann doch sehr aktiv zur dominierenden gemacht). Wahrscheinlich glaubt er sie (zumindest teilweise) selbst. In dieser Realität kann durchaus richtig sein (im ethischen wie im realpolitischen Sinn), was er macht, wenn er an der Macht bleiben will. Es ist vor allem aber eine zutiefst zynische Realität, zynisch nicht nur in Bezug auf (Macht-)Politik im Inneren und nach außen, sondern zynisch der Möglichkeit von ethisch und moralisch begründetem Handeln (in der Politik, also in der realen Welt) gegenüber.

Diesen und andere Texte finden Sie auf Jens Siegerts Russlandblog <http://russland.boellblog.org/>.

\section{Grafik 21: Putins Rating (\% der Befragten, die Putins Arbeit gutheißen)}

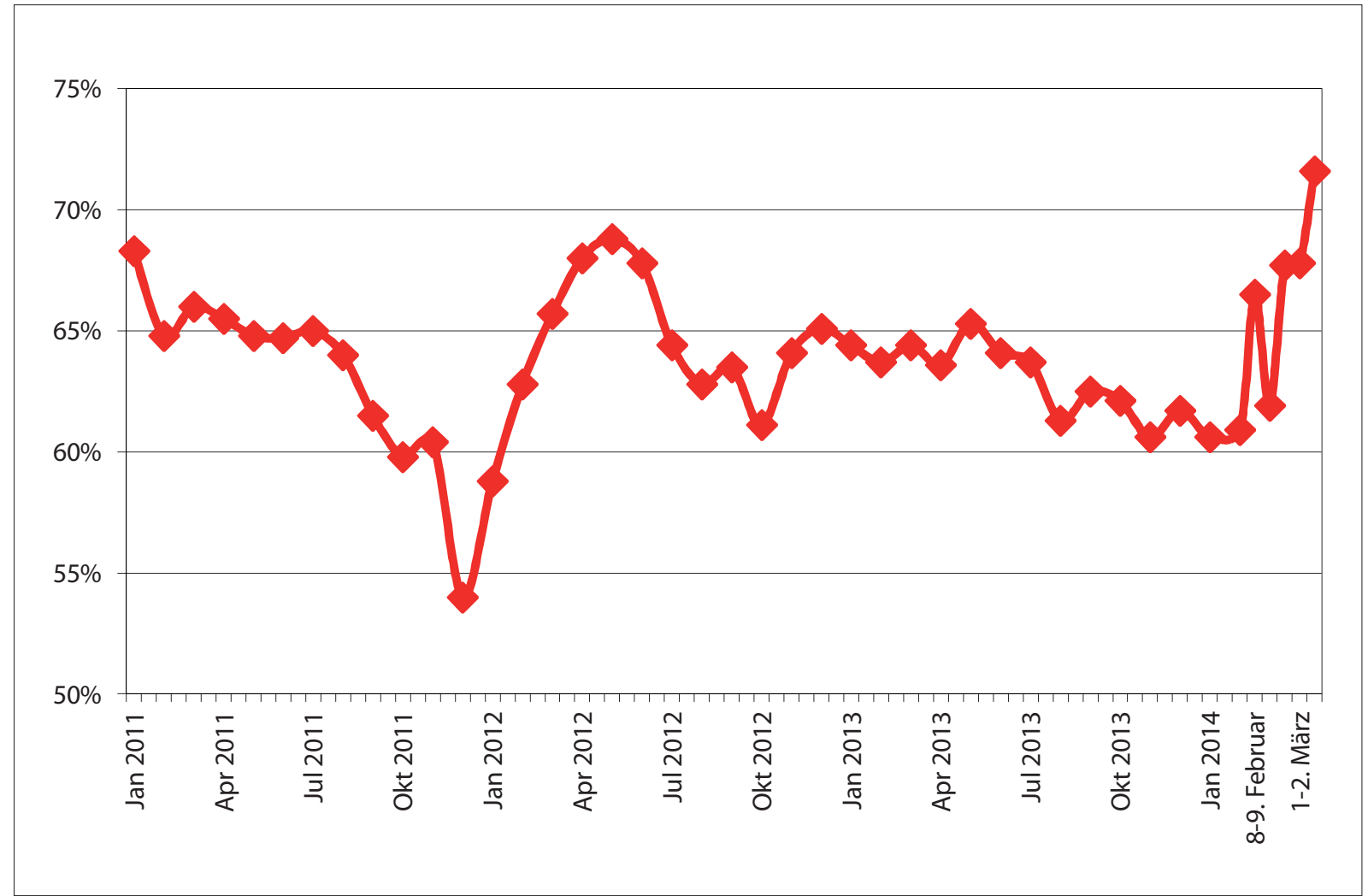

Quelle: Umfragen des WZIOM von Januar 2011 bis 8.-9. März 2014, N=1600. Veröffentlicht am 13. März 2014 unter: <http://wciom.ru/index.php?id=459\&uid=114742> 


\section{Februar - 13. März 2014}

\begin{tabular}{|c|c|}
\hline 28.02.2014 & $\begin{array}{l}\text { Der ukrainische Innenminister Arsen Awako beschuldigt Russland einer bewaffneten Invasion und bittet die } \\
\text { USA und Großbritannien, die Souveränität der Ukrainezu garantieren. Interimspräsident Alexander Turtschy- } \\
\text { now ruft eine Sondersitzung des ukrainischen Sicherheitsrates ein. Bewaffnete Einheiten ohne Erkennungszei- } \\
\text { chen haben die Flughäfen "Simferopol« und Belbek auf der Krim blockiert. Der ukrainische Telefonkonzern } \\
\text { „Ukrtelekom« teilt mit, dass die Telefonverbindung zwischen dem Festland und der Krim wegen Beschädigung } \\
\text { des optischen Faserkabels unterbrochen sei. }\end{array}$ \\
\hline 28.02 .2014 & Der ukrainische Ex-Präsident Viktor Janukowytsch gibt im russischen Rostow am Don eine Pressekonferenz. \\
\hline 28.02 .2014 & $\begin{array}{l}\text { Ein Moskauer Bezirksgericht wandelt das Reiseverbot gegen Alexej Nawalnyj in einen Hausarrest um, der bis } \\
\text { zum 28. April gilt. Die Verwendung sämtlicher Kommunikationsmittel, darunter des Internet, wird ihm unter- } \\
\text { sagt. Das russische Justizministerium registriert am gleichen Tag Nawalnyjs "Partei des Fortschritts« (Partija } \\
\text { Progressa). }\end{array}$ \\
\hline 28.02.2014 & $\begin{array}{l}\text { Das Moskauer Stadtgericht bestätigt die Verlängerung des Hausarrestes gegen Sergej Udalzow, des Vorsitzen- } \\
\text { den der "Linken Front«, sowie die Verlängerung der Untersuchungshaft gegen Leonid Raswosshajew bis zum } \\
\text { 10. Juni. Das Gericht lehnt einen Einspruch von Boris Nemzow (RPR-PARNAS) gegen seine Administrativ- } \\
\text { haft von } 10 \text { Tagen ab. }\end{array}$ \\
\hline 01.03 .2014 & $\begin{array}{l}\text { Die Ständige Vertreterin der USA bei den Vereinten Nationen Samantha Power erklärt, dass die USA eine Ver- } \\
\text { mittlermission auf der Krim für notwendig halten. Witalij Tschurkin, Ständiger Vertreter Russlands bei der } \\
\text { UN, erklärt, dass Russland gegen eine »aufgezwungene Vermittlermission« auf der Krim sei. }\end{array}$ \\
\hline 01.03 .2014 & $\begin{array}{l}\text { Sergej Aksjonow, Ministerpräsident der Krim, unterstellt sämtliche Sicherheitsstrukturen der autonomen Repu- } \\
\text { blik seiner Kommandogewalt, darunter die »Berkut«-Einheit, die im Rest der Ukraine aufgelöst wurde. Aksjo- } \\
\text { now bittet zudem Russlands Präsident Wladimir Putin, Beistand bei der Aufrechterhaltung von Frieden und } \\
\text { Ruhe auf dem Gebiet der autonomen Republik zu leisten. }\end{array}$ \\
\hline 01.03 .2014 & $\begin{array}{l}\text { Das Außenministerium Russlands äußert in einer Erklärung seine große Sorge über die jüngsten Ereignisse auf } \\
\text { der Krim. „Unbekannte Bewaffnete aus Kiew haben den Versuch unternommen, das Gebäude des Innenmi- } \\
\text { nisteriums der autonomen Republik Krim einzunehmen. In Folge der heimtückischen Provokation hat es Ver- } \\
\text { letzte gegeben. Dank des entschiedenen Vorgehens der Selbstverteidigungstruppen konnte der Versuch einer } \\
\text { Besetzung des Ministerium verhindert werden.» }\end{array}$ \\
\hline 01.03 .2014 & $\begin{array}{l}\text { Das Moskauer Stadtgericht bestätigt die administrative Haftstrafe von } 10 \text { Tagen gegen Ilja Jaschin (Solidar- } \\
\text { nost) wegen Teilnahme an einer nicht genehmigten Protestaktion. }\end{array}$ \\
\hline 01.03 .2014 & $\begin{array}{l}\text { Der Vorsitzende der russischen Staatsduma Sergej Naryschkin teilt mit, dass die Dumaabgeordneten Präsident } \\
\text { Wladimir Putin auffordern, »Maßnahmen zur Stabilisierung der Lage auf der Krim zu ergreifen und alle mög- } \\
\text { lichen Mittel einzusetzen, um die Bevölkerung der Krim vor Willkur und Gewalt zu schützen«. }\end{array}$ \\
\hline 01.03 .2014 & $\begin{array}{l}\text { Präsident Wladimir Putin ersucht den Föderationsrat, den Einsatz russischer Streitkräfte auf dem Territorium } \\
\text { der Ukraine bis zur Normalisierung der gesellschaftlichen und politischen Situation in diesem Land zu geneh- } \\
\text { migen. Der Föderationsrat stimmt dem Antrag einmütig zu. }\end{array}$ \\
\hline 02.03 .2014 & $\begin{array}{l}\text { US-Präsident Barack Obama äußert bei einem Telefongespräch mit Präsident Wladimir Putin seine Sorge über } \\
\text { einen möglichen Einsatz russischer Streitkräfte in der Ukraine. Putin betont die reale Gefahr für Leib und } \\
\text { Leben russischer Staatsbürger und Landsleute in der Ukraine. Russland behalte sich das Recht vor, seine Inte- } \\
\text { ressen und die der russischsprachigen Bevölkerung in der Ukraine zu schützen. }\end{array}$ \\
\hline 02.03 .2014 & $\begin{array}{l}\text { Im Moskauer Stadtzentrum nehmen offiziellen Angaben zufolge } 20.000 \text { Personen an einer Demonstration } \\
\text { "gegen die Provokateure, die in Kiew die Macht ergriffen haben« und zur Unterstützung der russischsprachi- } \\
\text { gen Bevölkerung in der Ukraine teil. In St. Petersburg nehmen rund } 1.000 \text { Personen unter der Losung "Der } \\
\text { Ukraine zur Hilfe« an einer Versammlung teil, die von der Regierungspartei "Einiges Russland« mitorganisiert } \\
\text { wurde. Auch in Krasnodar wird eine Versammlung abgehalten. }\end{array}$ \\
\hline 02.03 .2014 & $\begin{array}{l}\text { In Moskau demonstrieren rund } 500 \text { Personen auf dem Manegenplatz gegen einen Einmarsch auf der Krim. } \\
\text { Etwa } 200 \text { Personen werden festgenommen. Mehr als } 100 \text { Kriegsgegner werden bei Mahnwachen vor dem Ver- } \\
\text { teidigungsministerium festgenommen. Auch in St. Petersburg kommt es zu Antikriegsdemonstrationen und } \\
\text { Verhaftungen. }\end{array}$ \\
\hline 02.03 .2014 & $\begin{array}{l}\text { Patriarch Kirill wendet sich in einer Ansprache an das »ukrainische Kirchenvolk und den Metropoliten Onu- } \\
\text { frij«: „Eine weitere Polarisierung der Gesellschaft, eine Zunahme von Gewalt gegen friedliche Staatsbürger darf } \\
\text { nicht zugelassen werden. Es ist notwendig, der gesamten Bevölkerung ihre Rechte und Freiheiten zu garan- } \\
\text { tieren, darunter ihr Recht, auch an der Verabschiedung von schicksalhaften Entscheidungen teilzunehmen.» }\end{array}$ \\
\hline 02.03 .2014 & Die Botschafter Kanadas, Lettlands und Tschechiens werden aus Russland abgezogen. \\
\hline
\end{tabular}




\begin{tabular}{|c|c|}
\hline 02.03 .2014 & $\begin{array}{l}\text { Anders Fogh Rasmussen, Generalsekretär der NATO, gibt nach einer Sondersitzung der Allianz in Brüssel } \\
\text { bekannt, dass die NATO die territoriale Integrität der Ukraine unterstützen wird und beabsichtigt, mit Russ- } \\
\text { land im NATO-Russland-Rat Verhandlungen zu führen. Die NATO ruft alle Seiten zu einer Deeskalation } \\
\text { des Konfliktes auf. }\end{array}$ \\
\hline 03.03 .2014 & $\begin{array}{l}\text { Zur Eröffnung der Moskauer Börse stürzt der Rubel erneut deutlich ab und fällt auf ein neues historisches Tief } \\
\text { von 1:36,46 US-Dollar und 1:50,5 Euro. Der Aktienindex fällt zum Start des Handelstages um 3,92-4,28\%. }\end{array}$ \\
\hline 03.03 .2014 & $\begin{array}{l}\text { Die Partner Russlands in der G8 stellen ihre Vorbereitungen zur Teilnahme am G8 Gipfel im Juni in Sotschi } \\
\text { ein und rufen Russland dazu auf, in direkte Verhandlungen mit Kiew zu treten. }\end{array}$ \\
\hline 03.03 .2014 & $\begin{array}{l}\text { In Belgorod, Brjansk, Nowotscherkassk und Irkutsk finden Demonstrationen unter den Losungen » Wir lassen } \\
\text { die Unsrigen nicht fallen«, »Für das Brudervolk Ukraine«, »Ehre der `Berkut«", »Der Faschismus kommt nicht } \\
\text { durch« und »Putin - wir sind mit dir« statt. }\end{array}$ \\
\hline 03.03 .2014 & $\begin{array}{l}\text { Das russische Strafverfolgungskomitee eröffnet gegen Dmitrij Jarosch, den Anführer des ukrainischen »Rech- } \\
\text { ten Sektors«, ein Strafverfahren wegen öffentlicher Aufrufe zu Terror und Extremismus und fordert dessen Aus- } \\
\text { lieferung. Jarosch habe "antirussische Kräfte öffentlich zu extremistischen Handlungen und Terror auf russi- } \\
\text { schem Staatsgebiet aufgerufen«. }\end{array}$ \\
\hline 03.03 .2014 & $\begin{array}{l}\text { Alexej Wenediktow wird von den Angestellten des kritischen Radiosenders "Echo Moskvy« als Chefredakteur } \\
\text { wiedergewählt. Der Radiosender gehört zu »Gazprom-Media». }\end{array}$ \\
\hline 03.03 .2014 & $\begin{array}{l}\text { Greenpeace fordert die Rückgabe ihres Schiffes »Arctic-Sunrise». Dieses war nach einer Demonstration vor } \\
\text { einer Ölbohrplattform in der Petschorasee im September } 2013 \text { beschlagnahmt worden. }\end{array}$ \\
\hline 03.03 .2014 & $\begin{array}{l}\text { Präsident Wladimir Putin einigt sich telephonisch mit seinen Amtskollegen Nursultan Nasarbajew (Kasach- } \\
\text { stan) und Alexander Lukaschenko (Belarus) auf eine gemeinsame Erklärung, in der die Mitgliedsstaaten des } \\
\text { Obersten Eurasischen Wirtschaftsrates ihre Besorgnis über die Zuspitzung der Lage in der Ukraine ausdrücken. }\end{array}$ \\
\hline 04.03 .2014 & $\begin{array}{l}\text { Vor dem Hintergrund der Ereignisse in der Ukraine stellt die USA Handels- und Investitionsverhandlungen } \\
\text { mit Russland ein. Das Pentagon unterbricht zudem die Zusammenarbeit mit den russischen Streitkräften. }\end{array}$ \\
\hline 04.03 .2014 & $\begin{array}{l}\text { Präsident Wladimir Putin und Verteidigungsminister Sergej Schojgu ordnen an, dass die Streitkräfte des West- } \\
\text { lichen und Zentralen Militärbezirks nach Ende der außerplanmäßigen Militärübungen am 7. März in ihre } \\
\text { Kasernen zurückkehren. }\end{array}$ \\
\hline 04.03 .2014 & $\begin{array}{l}\text { In Woronesh, Kostroma und Irkutsk finden Demonstrationen zur Unterstützung der russischsprachigen Lands- } \\
\text { leute in der Ukraine statt. }\end{array}$ \\
\hline 04.03 .2014 & $\begin{array}{l}\text { Das oppositionelle »Komitee für Protestaktionen« beantragt eine Antikriegsdemonstration am 15. März im } \\
\text { Zentrum Moskaus für } 50.000 \text { Teilnehmern. }\end{array}$ \\
\hline 04.03 .2014 & $\begin{array}{l}\text { Der »Gazprom«-Chef Alexej Miller teilt bei einem Treffen mit Ministerpräsident Dmitrij Medwedew mit, dass } \\
\text { die Reduzierung des Gaspreises (von } \$ 410 \text { auf } \$ 268,5 / \text { Tsd. } \mathrm{m}^{3} \text { ), die Mitte Dezember mit dem ehemaligen ukrai- } \\
\text { nischen Präsidenten Viktor Janukowytsch vereinbart wurde, ab April wieder ausgesetzt wird. }\end{array}$ \\
\hline 04.03. & $\begin{array}{l}\text { Natalja Sindejewa, Generaldirektorin des kritischen TV-Senders »TV-Doshd« erklärt, dass der Sender aus finan- } \\
\text { ziellen Gründen in einem Monat schließen muss. }\end{array}$ \\
\hline 04.03 .2014 & $\begin{array}{l}\text { Präsident Wladimir Putin gibt eine Pressekonferenz zur Situation in der Ukraine und auf der Krim. Putin } \\
\text { erklärt, Janukowytsch sei weiterhin legitimer Präsident der Ukraine, habe jedoch keine politische Zukunft } \\
\text { mehr. Den Machtwechsel in der Ukraine bezeichnet Putin als "verfassungsfeindlichen Umsturz und bewaff- } \\
\text { nete Machtübernahme«. Die Zukunft der Krim sei Sache ihrer Bewohner, Russland werde die Situation nicht } \\
\text { anheizen. Russland setze dort keine Soldaten ein. }\end{array}$ \\
\hline 04.03 .2014 & $\begin{array}{l}\text { Das russische Verteidigungsministerium meldet den erfolgreichen Start der Interkontinentalrakete RS-12M } \\
\text { »Topol« vom Truppenübungsplatz «Kapustin Jar« im Gebiet Astrachan. }\end{array}$ \\
\hline 05.03 .2014 & $\begin{array}{l}\text { Der Premierminister Kanadas Steven Harper gibt bekannt, dass Kanada die militärische Zusammenarbeit mit } \\
\text { Russland einstelle. }\end{array}$ \\
\hline 05.03 .2014 & $\begin{array}{l}\text { Die Vorsitzenden von mehr als } 40 \text { russischen Medienunternehmen bitten Präsident Wladimir Putin in einem } \\
\text { offenen Brief, die deutliche Erhöhung der Postgebühren (ab Juli um das zwei- bis dreifache) für die Zustel- } \\
\text { lung von Printmedien abzuwenden und die Subventionen für die Zustellung von Abonnements an die russi- } \\
\text { sche Post aufrecht zu erhalten. }\end{array}$ \\
\hline 05.03 .2014 & $\begin{array}{l}\text { Der russische Transportminister Maxim Sokolow schätzt die Kosten des von Medwedew zwei Tage zuvor beauf- } \\
\text { tragen Baus der Brücke über die Straße von Kertsch (als Verbindung zwischen Russland und der Krim) auf } \\
\text { mindestens } 50 \text { Mrd. Rubel (aktuell rund } 1 \text { Mrd. €) und einer Bauzeit von mindestens dreieinhalb Jahre. Med- } \\
\text { wedew hatte } 3 \text { Mrd. US-Dollar zugesagt. }\end{array}$ \\
\hline 05.03 .2014 & $\begin{array}{l}\text { Rustam Minnichanow, Oberhaupt der Republik Tatarstan, unterzeichnet bei einem Treffen mit Sergej Aksjo- } \\
\text { now, dem Vorsitzenden des Ministerrats der autonomen Republik Krim, eine Vereinbarung zur wirtschaftli- } \\
\text { chen und humanitären Zusammenarbeit zwischen Tatarstan und der Krim. }\end{array}$ \\
\hline
\end{tabular}




\begin{tabular}{|c|c|}
\hline 06.03 .2014 & $\begin{array}{l}\text { Rustam Temirgaliev, Stellvertretender Ministerpräsident der Autonomen Republik Krim, gibt bekannt, dass } \\
\text { das Referendum über den Status der Krim auf den 16. März vorverlegt wird. Die Bewohner der Krim haben } \\
\text { die Auswahl zwischen 1. einer Angliederung der Krim an Russland als Föderationssubjekt und 2. der Wieder- } \\
\text { herstellung der Verfassung von 1992, die der Krim weitere Autonomierechte gewährt. Der Oberste Sowjet der } \\
\text { Republik Krim spricht sich für einen Beitritt zu Russland als Föderationssubjekt aus und bittet Präsident Putin } \\
\text { und die Föderalversammlung, das Beitrittsverfahren aufzunehmen. }\end{array}$ \\
\hline 06.03 .2014 & $\begin{array}{l}\text { Sitzung des russischen Sicherheitsrates. Im Zentrum stehen die Entwicklungen in der Ukraine sowie die Ent- } \\
\text { scheidung des Obersten Sowjets der Krim für einen Beitritt der Krim zu Russland als Föderationssubjekt. }\end{array}$ \\
\hline 06.03 .2014 & $\begin{array}{l}\text { Mehrere Hundert Menschen kommen in Jekaterinburg zu einer »Volksversammlung `Für das Brudervolk!« } \\
\text { zusammen. Als Organisator tritt die Gesellschaftskammer im Gebiet Swerdlowsk auf. Sichtbare Teilnehmer } \\
\text { sind Kosaken und Vertreter von Parteien und gesellschaftlicher Organisationen. }\end{array}$ \\
\hline 06.03 .2014 & $\begin{array}{l}\text { Das russische Justizministerium untersagt der NGO „Für die Menschenrechte» (Lew Ponomarjow) jegliche } \\
\text { Tätigkeit und erklärt, dass diese sechs Monate Zeit habe, die beanstandeten Mängel insbesondere in der Sat- } \\
\text { zung zu beheben. }\end{array}$ \\
\hline 06.03 .2014 & $\begin{array}{l}\text { Die EU beschliesst, die Verhandlungen mit Russland über ein Wirtschaftsabkommen und Visaerleichterun- } \\
\text { gen auszusetzen. Strengere Sanktionen würden folgen, sollte Russland die Krise verschärfen. Wladimir Tschi- } \\
\text { show, ständiger Vertreter Russland bei der EU, reagiert auf die Ergebnisse des EU-Sondergipfels zur Situation } \\
\text { in der Ukraine: Wenn irgendjemand glaube, mit solchen Gruselgeschichten könne man Russland erschrecken, } \\
\text { dann irre er sich gewaltig. }\end{array}$ \\
\hline 06.-07.03.2014 & Der Sprecher des UN-Sicherheitsrates erklärt, dass dieser das Referendum auf der Krim für rechtswidrig ansehe. \\
\hline 07.03 .2014 & $\begin{array}{l}\text { Das Weiße Haus in Washington verhängt Visa-Sanktic } \\
\text { Souveränität und territoriale Integrität der Ukraine« ges }\end{array}$ \\
\hline 07.03 .2014 & $\begin{array}{l}\text { Präsident Wladimir Putin entlässt Alexej Gordejew, dem Gouverneur des Gebiets Woronesh, mit dem Auslau- } \\
\text { fen seiner Amtszeit, ernennt ihn aber zum Interimsgouverneur des Gebietes. }\end{array}$ \\
\hline 07.03 .2014 & $\begin{array}{l}\text { Es kommt zu Hackerangriffen auf russische Medieninstitutionen. Die Internetseite der »Rossijskaja Gaseta» } \\
\text { wird über mehrere Stunden hinweg lahm gelegt. Parallel dazu werden die Internetseiten der kritischen Zeit- } \\
\text { schriften »Russkij Reporter« und »Ekspert« durch DDoS-Angriffe blockiert. }\end{array}$ \\
\hline 07.03 .2014 & $\begin{array}{l}\text { Sergej Naryschkin, Vorsitzender der russischen Staatsduma, empfängt Wladimir Konstantinow, den Vorsitzen- } \\
\text { den des Obersten Sowjets der autonomen Republik Krim in der Staatsduma. An dem Treffen nehmen zudem } \\
\text { die Franktionsvorsitzenden oder deren Stellvertreter aller Duma-Parteien sowie der Vorsitzende des Duma-Aus- } \\
\text { schusses für GUS-Angelegenheiten teil. Konstantinow erklärt, dass die Staatsmacht der Krim internationale } \\
\text { Wahlbeobachter zum Referendum am 16. März einlädt, insbesondere aus Russland. }\end{array}$ \\
\hline 07.03 & $\begin{array}{l}\text { Die Moskauer Polizei teilt mit, dass mehr als } 65.000 \text { Personen an einer Versammlung zur Unterstützung der } \\
\text { Bewohner auf der Krim im Moskauer Stadtzentrum teilnehmen. Auf der Versammlung sind Flaggen von } \\
\text { „Einiges Russland«, ihrer Jugendorganisationen, Hochschulen, und mehrerer staatsnaher Verbände zu sehen. }\end{array}$ \\
\hline 07.03 .2014 & $\begin{array}{l}\text { Die russische Regierung vereinfacht die Vergabe der russischen Staatsbürgerschaft an Ausländer, wenn diese } \\
\text { die russische Sprache regulär im kulturellen, gesellschaftlichen und familiärem Umfeld verwenden, deren Vor- } \\
\text { fahren oder sie selbst auf dem Gebiet Russlands, der Sowjetunion oder des Russischen Reiches gelebt haben, } \\
\text { sowie bereit sind, ihre bisherige Staatsbürgerschaft abzugeben bzw. die staatenlos sind. }\end{array}$ \\
\hline 07.03 .2014 & $\begin{array}{l}\text { in Moskauer Bezirksgericht verurteilt Alexej Nawalnyj zu einer Geldstrafe von } 10.000 \text { Rubel (ca. } 200 €) \text {. Nawal- } \\
\text { j habe bei Protesten gegen das Urteil im »Bolotnaja-Verfahren« gegen die Versammlungsordnung verstoßen. }\end{array}$ \\
\hline 07.03 .2014 & $\begin{array}{l}\text { In Sotschi findet die Eröffnungszeremonie der XI. Paralymischen Winterspiele statt. Im Anschluss werden die } \\
\text { Spiele, die bis zum 16. März andauern, offiziell eröffnet. }\end{array}$ \\
\hline 08.03 .2014 & $\begin{array}{l}\text { Grigorij Karasin, Stellvertretender Außenminister, trifft mit Wladimir Jeltschenko, dem ukrainischen Bot- } \\
\text { schafter in Russland, zusammen, um über die bilateralen Beziehungen zu sprechen. }\end{array}$ \\
\hline 08.03 .2014 & $\begin{array}{l}\text { Dmitrij Rogosin, Vize-Ministerpräsident und Beauftragter für den Militär-Industriellen Komplex erklärt, dass } \\
\text { nach den »offenen Drohungen der USA und der NATO hoffentlich niemand mehr an der Notwendigkeit einer } \\
\text { schnellstmöglichen Neubewaffnung unserer Armee und Flotte sowie der Wiederbelebung der heimischen Rüs- } \\
\text { tungsindustrie und Militärforschung zweifelt würde." }\end{array}$ \\
\hline 09.03 .2014 & $\begin{array}{l}\text { Präsident Wladimir Putin bespricht in Telefonaten mit dem britischen Premierminister David Cameron und } \\
\text { mit Bundekanzlerin Angela Merkel die Situation in der Ukraine und das Referendum auf der Krim. }\end{array}$ \\
\hline 10.03 .2014 & $\begin{array}{l}\text { In Wologda versammeln sich ca. } 5.500 \text { Personen um ihre Solidarität mit der russischsprachigen Bevölkerung } \\
\text { der Ukraine und der Krim sowie mit der Politik Russlands auszudrücken }\end{array}$ \\
\hline 10.03 .2014 & $\begin{array}{l}\text { nminister Sergej Lawrow teilt mit, dass US-Außenminister John Kerry seine für diesen Tag geplante Mos- } \\
\text { isite verschoben hat. }\end{array}$ \\
\hline
\end{tabular}




\begin{tabular}{|c|c|}
\hline 10.03.2014 & $\begin{array}{l}\text { Der Oberste Sowjet der autonomen Republik Krim überträgt die Vollmachten des Oberkommandeurs der } \\
\text { Streitkräfte der Republik auf Ministerpräsident Sergej Aksjonow. Aksjonow teilt im Anschluss mit, dass die } \\
\text { Nationalisierung der Ukrainischen Kriegsflotte auf der Krim und von "TschernomorNeftegas« (ukrainischer } \\
\text { Staatskonzern zur Erkundung, Förderung, Transport und Lagerung von Öl und Gas im ukrainischen Schwarz- } \\
\text { meersektor) und weitere Staatsobjekte zur Bodennutzung geplant sei. }\end{array}$ \\
\hline 10.03.2014 & $\begin{array}{l}\text { Die fünfte Sitzung, die der UN-Sicherheitsrat in den letzten zehn Tagen zur Situation in der Ukraine durch- } \\
\text { führt, endet abermals ergebnislos. }\end{array}$ \\
\hline 11.03 .2014 & $\begin{array}{l}\text { In Russland tritt ein Erlass des Dienstes zur Regulierung des Alkoholmarktes in Kraft, wonach der Mindest- } \\
\text { preis für einen halben Liter Wodka von } 170 \text { auf } 199 \text { Rubel und ab dem 1. August auf } 220 \text { Rubel (3,36-3,39 } \\
-4,34 € \text { ) angehoben wird. Der Mindestpreis für 0,5 Liter Kognak steigt zum 11. März von } 293 \text { auf } 322 \text { Rubel } \\
\text { (von 5,77 auf } 6,36 € \text { ). }\end{array}$ \\
\hline 11.03 .2014 & $\begin{array}{l}\text { Das Moskauer Bürgermeisteramt übernimmt die Wochenzeitung "Argumenty i fakty«. Die Zeitung hatte rote } \\
\text { Zahlen geschrieben und geht nun samt Schuldenberg und Immobilien in die Hände der Stadtverwaltung über. }\end{array}$ \\
\hline 11.03 .2014 & $\begin{array}{l}\text { Mehr als } 250 \text { russische Kulturschaffende unterzeichnen eine Erklärung zur Unterstützung von Präsident Wla- } \\
\text { dimir Putin und seiner Politik gegenüber der Ukraine und der Krim. Die Erklärung wird auf der Internetseite } \\
\text { des Kulturministeriums <http://mkrf.ru> und in sozialen Netzwerken veröffentlicht. }\end{array}$ \\
\hline 11.03 .2014 & $\begin{array}{l}\text { Der ukrainische Ex-Präsident Viktor Janukowytsch gibt im russischen Rostow am Don eine Erklärung ab. } \\
\text { Demnach versteht er sich als der legitime Präsident und Oberbefehlshaber des Landes. Die neue Regierung } \\
\text { bezeichnet er als Ultranationalisten und Profaschisten. }\end{array}$ \\
\hline 11.03 .2014 & ublik Krim verabschiedet eine Unabhängigkeitserklärung als juristi- \\
\hline 12.03 .2014 & $\begin{array}{l}\text { Der Schweizer Bundespräsident Didier Burkhalter veröffentlicht in seiner Funktion als derzeitiger Vorsitzen- } \\
\text { der der OSZE eine Erklärung, in der das für den 16. März angesetzte Referendum auf der Krim für illegitim } \\
\text { erklärt wird. Präsident Wladimir Putin telefoniert am Abend mit Burkhalter und lotet Vermittlungsoptionen } \\
\text { der OSZE zur Regulierung der Krise aus. }\end{array}$ \\
\hline 12.03 .2014 & $\begin{array}{l}\text { Alexander Mamut, Besitzer des Medienunternehmens »Afischa-Rambler-SUP» entlässt die Chefredakteurin } \\
\text { des Online-Nachrichtenportals »Lenta.ru«, Galina Timtschenko. »Lenta.ru« war vom »Russischen Dienst zur } \\
\text { Aufsicht der Massenmedien« wegen einer Publikation über den ukrainischen »Rechten Sektor» (»Wir sind keine } \\
\text { bewaffneten Kräfte») verwarnt worden. Als Nachfolger wird Alexej Goreslawskij ernannt, der zuvor stellvertre- } \\
\text { tender Generaldirektor von Mamuts Medienholding war. }\end{array}$ \\
\hline 13.03.2014 & $\begin{array}{l}\text { Die Pressestelle des russischen Verteidigungsministeriums gibt bekannt, dass auf Truppenübungsplätzen im } \\
\text { Südwesten Russlands, in den Gebieten Rostow, Belgorod, Tambow und Kursk Mobilisierungs- und anschlie- } \\
\text { ßende Gefechtsübungen durchgeführt werden. }\end{array}$ \\
\hline 13.03 .2014 & Die Moskauer Stadtverwaltung genehmigt einen »Friedensmarsch» mit 50.000 Teilnehmern am 15. März . \\
\hline 13.03 & \\
\hline 13.03.2014 & $\begin{array}{l}\text { gibt bekannt, dass sie den Beitrittsprozess mit Russland auf die Bitte mehrerer Mitgliedsstaaten } \\
\text { th hat. }\end{array}$ \\
\hline
\end{tabular}

Sie können die gesamte Chronik seit 1964 auch auf http://www.laender-analysen.de/russland/ unter dem Link»Chronik«lesen.

Die Russland-Analysen werden von der Alfried Krupp von Bohlen und Halbach-Stiftung und von Mangold Consulting GmbH unterstützt.

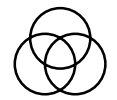

\section{Alfried Krupp von Bohlen und Halbach Stiftung}

\section{MANGOLD

Herausgeber: Forschungsstelle Osteuropa an der Universität Bremen und Deutsche Gesellschaft für Osteuropakunde

Die Meinungen, die in den Russland-Analysen geäußert werden, geben ausschließlich die Auffassung der Autoren wieder. Abdruck und sonstige publizistische Nutzung sind nach Rücksprache mit der Redaktion gestattet. Verantwortlicher Redakteur: Hans-Henning Schröder

Recherche, Übersetzungen und Sprachredaktion: Christoph Laug, Hartmut Schröder Satz: Matthias Neumann

Russland-Analysen-Layout: Cengiz Kibaroglu, Matthias Neumann und Michael Clemens

Alle Ausgaben der Russland-Analysen sind mit Themen- und Autorenindex archiviert unter www.laender-analysen.de

Die Russland-Analysen werden im Rahmen eines Lizenzvertrages in das Internetangebot der Bundeszentrale für politische Bildung (www.bpb.de) aufgenommen.

Die Russland-Analysen werden im Rahmen der Datenbank World Affairs Online (WAO) ausgewertet und sind im Portal IREON www.ireon-portal.de recherchierbar. ISSN 1613-3390 @ 2014 by Forschungsstelle Osteuropa, Bremen

Forschungsstelle Osteuropa • Publikationsreferat • Klagenfurter Str. 3 • 28359 Bremen • Telefon: +49 421-218-69600 • Telefax: + 49 421-218-69607 e-mail: publikationsreferat@osteuropa.uni-bremen.de•Internet-Adresse: http://www.laender-analysen.de/russland/ 


\section{Kostenlose E-Mail-Dienste der Forschungsstelle Osteuropa und ihrer $\square$ Partner auf www.laender-analysen.de}

Die Länder-Analysen bieten regelmäßig kompetente Einschätzungen aktueller politischer, wirtschaftlicher, sozialer und kultureller Entwicklungen in Ostmitteleuropa und der GUS. Sie machen das Wissen, über das die wissenschaftliche Forschung in reichem Maße verfügt, für Politik, Wirtschaft, Medien und die interessierte Öffentlichkeit verfügbar. Autoren sind internationale Fachwissenschaftler und Experten.

Die einzelnen Länder-Analysen werden von der Forschungsstelle Osteuropa an der Universität Bremen und der Deutschen Gesellschaft für Osteuropakunde jeweils mit unterschiedlichen Partnern und Sponsoren herausgegeben.

Die Länder-Analysen bieten regelmäßig Kurzanalysen zu aktuellen Themen, ergänzt um Grafiken und Tabellen sowie Dokumentationen. Zusätzlich gibt es eine Chronik aktueller Ereignisse.

\section{Belarus-Analysen}

Erscheinungsweise: zweimonatlich

Abonnement unter: fsopr@uni-bremen.de

\section{Caucasus Analytical Digest}

In englischer Sprache. Erscheinungsweise: monatlich

Abonnement unter: <http://www.res.ethz.ch/analysis/cad/>

\section{Polen-Analysen}

Erscheinungsweise: zweimal monatlich

Abonnement unter: <http://www.deutsches-polen-institut.de/Newsletter/subscribe.php>

\section{Russland-Analysen}

Erscheinungsweise: zweiwöchentlich

Abonnement unter: fsopr@uni-bremen.de

\section{Russian Analytical Digest}

In englischer Sprache. Erscheinungsweise: zweimal monatlich

Abonnement unter: <http://www.res.ethz.ch/analysis/rad/>

\section{Ukraine-Analysen}

Erscheinungsweise: zweimal monatlich

Abonnement unter: fsopr@uni-bremen.de

\section{Zentralasien-Analysen}

Erscheinungsweise: monatlich

Abonnement unter: zentralasien-analysen@dgo-online.org

\section{Bibliographische Dienste}

Die Bibliographien informieren über englisch- und deutschsprachige Neuerscheinungen zu Belarus, Polen, Russland, Tschechischer und Slowakischer Republik, Ukraine sowie zu den zentralasiatischen und kaukasischen Staaten. Erfasst werden jeweils die Themenbereiche Politik, Außenpolitik, Wirtschaft und Soziales.

Erscheinungsweise: viermal jährlich

Abonnement unter: fsopr@uni-bremen.de

\section{Twitter}

<https://twitter.com/laenderanalysen> 